\title{
Identification and Prediction of Allo-Source Overpressure Caused by Vertical Transfer: Example from an HTHP Gas Reservoir in the Ledong Slope in the Yinggehai Basin
}

\author{
Caiwei Fan, ${ }^{1}$ Changgui Xu $\left(\mathbb{D},{ }^{1}\right.$ Chao Li $\mathbb{D}^{2},{ }^{2}$ Aiqun Liu, ${ }^{1} \mathrm{Hu} \mathrm{Li},{ }^{1}$ Jingxian Hou, ${ }^{1}$ \\ Xiaoying Zhang $\left({ }^{3},{ }^{3}\right.$ Bin $\mathrm{Lu}\left(\mathbb{D},{ }^{3}\right.$ and Jun $\mathrm{Li}\left(\mathbb{C}^{4}\right.$ \\ ${ }^{1}$ Zhanjiang Branch of China National Offshore Oil Corporation Ltd., Zhanjiang 524057, China \\ ${ }^{2}$ Key Laboratory of Petroleum Resources Research, Institute of Geology and Geophysics, Chinese Academy of Sciences, \\ Beijing 100029, China \\ ${ }^{3}$ Dimue Technologies Limited, Wuhan 430071, China \\ ${ }^{4}$ School of Earth Resources, China University of Geosciences (Wuhan), Wuhan 430074, China
}

Correspondence should be addressed to Chao Li; lichaocpu@126.com

Received 31 December 2020; Revised 17 March 2021; Accepted 15 April 2021; Published 27 April 2021

Academic Editor: Jinze Xu

Copyright (c) 2021 Caiwei Fan et al. This is an open access article distributed under the Creative Commons Attribution License, which permits unrestricted use, distribution, and reproduction in any medium, provided the original work is properly cited.

The Yinggehai Basin is a typical high temperature and high pressure (HTHP) gas-bearing basin. The pressure coefficient exceeds 2.2 in deeply-buried Miocene reservoirs in the Ledong Slope, a nondiapir zone in the Yinggehai Basin. Determining the overpressure mechanisms and predicting the pore pressure are key issues for natural gas exploration and development in the Ledong Slope. In this paper, overpressure mechanisms were investigated according to the analysis of vertical effective stress-logging responses and geological evaluations, and the pore pressure was predicted using the Bowers method. The loading-unloading crossplots indicated that the overpressure that existed in reservoirs mainly consists of two types: neighbor-source and allo-source overpressure. The neighbor-source overpressure is mainly caused by the pressure transmission from the adjacent mudstone to the reservoir, with a pressure coefficient less than $1.5 \sim 1.6$. The high-magnitude overpressure points with pressure coefficients greater than 1.6 show a typical unloading response, indicating elevated sandstone pressures rather than in situ mudstone pressures, which are most likely to be generated by overpressure vertical transfer. The high-magnitude overpressure fluid generated by the high mature ultradeep buried $\mathrm{N}_{1} \mathrm{~s}$ source rock migrated to the shallower reservoirs via hidden faults/microfractures, which led to the vertical transfer of overpressure. Vertically transferred overpressure was generated at $1.5 \sim 0.2 \mathrm{Ma}$, which is beneficial for the preservation of overpressure in lenticular sandbodies. The estimated pore pressure by the Bowers method is in good agreement with the measured pressure and provides a meaningful reference for predrilling pressure prediction in nondiapir or diapir zones in the Yinggehai Basin.

\section{Introduction}

The pore pressure is called abnormally high pressure or overpressure when it is greater than the hydrostatic pressure expected at a given depth $[1,2]$. Great risk can be posed due to unexpected overpressure zones during drilling operations, which is harmful to both human life and environment $[3,4]$. Significant progress has been made in research on the origin of overpressure and pore pressure prediction in lowpermeability formations. The low-permeability mudstones play a critical role in the generation and preservation of abnormal pressure $[1,3,5]$. In situ overpressures in sedimentary basins are commonly attributed to disequilibrium compaction or fluid expansion (gas generation) $[1-3,5,6]$. Generally, the overpressure in mudstone cannot be sustained for long periods of geological time, with the overpressure dissipating via fluid leakage [7-9].

The overpressure redistribution phenomenon commonly occurs in permeable aquifers. It is equally important to research the redistribution of overpressure as it is to under- 
stand the overpressure mechanism. According to pore fluid sources, overpressure in permeable formations can be divided into three types: self-source, neighbor-source, and allo-source overpressure [10]. Self-source overpressure is caused by the buoyancy of the hydrocarbon column, oil-to-gas cracking, precipitation of dissolved gas $[3,5,10]$. Neighbor-source overpressure refers to the overpressure phenomenon in permeable formations caused by the transmission of pressure from adjacent high-pressure low-permeability formations, and the pressure in the mudstone is equal to that in the sandstone. Commonly used pressure prediction methods including the equivalent depth method and Eaton method can be successfully applied to the prediction of neighbor-source overpressure $[11,12]$. Allo-source overpressure means that the pressure results from the overpressure transfer due to the hydrodynamic connection between different overpressure systems, including lateral transfer in inclined laterally continuous sandstones (centroid effect) and vertical transfer via opening faults $[7,13,14]$. In particular, faults can extend to ultradeep highmagnitude overpressure systems, which lead to a very high overpressure in shallow permeable formations [15].

The vertical effective stress-porosity/sonic velocity plots (also known as loading-unloading curves) are used to distinguish between neighbor-source overpressure and allo-source overpressure $[3,7,16,17]$. Pore pressures relate to disequilibrium compaction commonly parallel to vertical stress; consequently, the vertical effective stress remains constant with burial, thus, the relationship will remain on the loading curve. While the increasing pore pressure causes the vertical effective stress to decrease when formations become overpressured either by fluid expansion or vertical transfer. However, the compaction is mostly an irreversible process, overpressures generated by fluid expansion or vertical transfer that follow a path away from the loading curve $[18,19]$. Unfortunately, the loading-unloading analysis cannot distinguish between the fluid expansion and vertical transfer mechanisms [3, 7].

Accurate prediction of allo-source overpressure is another difficult issue during drilling engineering [20, 21]. Vertically transferred overpressure is always generated after normal compaction of formations, which is only associated with a small change in porosity because of the slight elastic contraction of sediment grains [19]. The sonic log response is smaller in sediments where overpressure is generated by vertical transfer. Tingay et al. [2] attempted to predict vertically transferred overpressure using the Eaton method and proposed that a higher Eaton exponent is required to amplify the weak sonic log response. However, the larger Eaton exponent also amplifies any small sonic variation not associated with overpressure, resulting in a noisy pore pressure prediction in hydrostatic and slightly overpressure sediment. The Eaton method seems cannot satisfactorily deal with the problems of vertically transferred overpressure prediction.

As a whole, although allo-source overpressure caused by pressure transfer is not a new observation, the lateral or vertical transfer of overpressure within sedimentary basins has not been widely reported, with a few notable exceptions [7, $15,17,20-22]$. At present, studies on allo-source overpressure are mostly limited to the qualitative description of measured overpressure characteristics and the possible generation process. The identification and accurate prediction of transfer overpressure using measured pressure and logging data are still weaknesses in overpressure research.

The Yinggehai Basin is a typical high temperature and high pressure (HTHP) basin with rich natural gas resources and is as famous as the Gulf of Mexico and North Sea Basin. The overpressure origins in the Gulf of Mexico and North Sea Basin have been thoroughly studied by researchers and recognized that the disequilibrium compaction, gas generation, and chemical compaction are dominated overpressure mechanisms [23-26]. However, the temperature and pore pressure in Yinggehai Basin is higher than that in the Gulf of Mexico and North Sea Basin, and the overpressure mechanism is more complicated. The highest temperature in the Yinggehai Basin is approximately $250^{\circ} \mathrm{C}$, and the pressure coefficient reaches 2.38. The depth of overpressure is shallow, overpressure increases quickly with depth, and the safety drilling window is very narrow [27]. Some studies have incorporated detailed petrophysical, geochemical, geophysical, and basin modeling into the analysis of the overpressure mechanism and prediction in the Yinggehai Basin [28-31]. It has been recognized that the disequilibrium compaction of mudstone caused by high deposition rates since the Miocene is the most common mechanism of overpressure in the Yinggehai Basin $[15,28,30]$. The overpressure contribution of hydrocarbon generation is negligible in the Miocene formations that buried shallower than $4500 \mathrm{~m}$ [15]. The development of high-magnitude overpressure in the shallow permeable sandstone is closely related to overpressure transfer by opening faults $[15,28]$. In particular, the mud diapir structures in the Yinggehai Basin have greatly changed the distribution pattern of pore pressure $[29,32]$. The overpressure is transferred from the deep overpressure system in the diapir belt to the shallow system through faults and fractures, which leads to the development of overpressure in shallow reservoirs [15, 28, 32]. Self-source overpressure caused by disequilibrium compaction is believed to be the most important overpressure mechanism in the nondiapir zone [31]. Previous researchers have tried to improve the existing prediction methods, but due to the complex mechanism of overpressure and the puzzling logging response of overpressure, overpressure prediction in the Yinggehai Basin still has difficulty meeting the needs of safe drilling, which easily causes overflow leakage or even blowout $[33,34]$.

In recent years, the exploration focus of the Yinggehai Basin has begun to shift to lithologic reservoirs in the Ledong Slope, which shows a large burial depth (more than $4000 \mathrm{~m}$ ), high temperature (a temperature greater than $200^{\circ} \mathrm{C}$, and a temperature gradient reaching $46.8^{\circ} \mathrm{C} / \mathrm{km}$ ), and high overpressure (a pressure coefficient close to 2.30) [35]. There have been few detailed studies on the mechanism of overpressure generation in the LD-B Wellblock until now. Considering that the Ledong Slope is located in nondiapir zone, researchers attribute the mechanism of overpressure in LDB Wellblock to disequilibrium compaction and hydrocarbon generation $[31,36]$. However, the equivalent depth method and Eaton method hardly accurately determine the pore pressure $[34,36]$. In addition, it is difficult to reasonably 
explain why the pore pressure among the same sandbodies shows obvious differences in different wells. In fact, the pore pressure of the deep buried reservoirs in the LD-B Wellblock is controlled by sedimentary and burial conditions, sandbody connectivity, and fault activity [35]. There are multiple overpressure mechanisms, and it is difficult to predict and monitor the pore pressure. Therefore, it is worth further understanding the overpressure mechanisms of the LD-B Wellblock.

This paper identifies the intrinsic mudstone pressure and determines whether the reservoir pressures are appropriate or anomalous using loading-unloading curves combined with 1-D basin modeling. The possibility of vertically transferred overpressure is confirmed with geological condition analysis. On this basis, the pressure prediction model parameters are optimized to realize the accurate prediction of the allo-source overpressure. The results of this study are expected to reduce possible accident such as kicks and blowouts during drilling to ensure drilling safety and to provide effective guidance for developing oil and gas resources.

\section{Geological Setting}

The Yinggehai Basin is a Cenozoic sedimentary basin located in the South China Sea and is diamond-shaped along the northwest-southeast direction, which is controlled by the Honghe strike-slip fault. The northeastern side of the basin is adjacent to the Beibuwan Basin and Hainan Island, and it is connected to the Kuntum Uplift to the west and the Qiongdongnan Basin to the southeast. The Yinggehai Basin is further divided into the Hanoi Depression, Lingao Uplift, Eastern Slope, Central Depression, and Western Slope. Due to dextral strike-slip, rows of left-order enechelon diapir structures with nearly north-south strikes are developed in the Central Depression, namely, the Central Mud Diapir Belt (Figure 1(a)). The LD-B Wellblock is in the southeastern part of the central depression of the Yinggehai Basin (Figure 1(b)), and the average seawater depth is approximately $85 \mathrm{~m}$. The tectonic evolution in the Yinggehai Basin may be divided into two stages: the Paleogene rifting stage and the NeogeneQuaternary postrifting thermal subsiding stage.

The thickness of the Cenozoic sedimentary strata in the Yinggehai Basin is more than $17 \mathrm{~km}$ and consists of the Oligocene Yacheng Formation $\left(\mathrm{E}_{3} \mathrm{y}\right)$ and Lingshui Formation $\left(\mathrm{E}_{3} \mathrm{l}\right)$; the Miocene Sanya Formation $\left(\mathrm{N}_{1} \mathrm{~s}\right)$; Meishan Formation $\left(\mathrm{N}_{1} \mathrm{~m}\right)$ and Huangliu Formation $\left(\mathrm{N}_{1} \mathrm{~h}\right)$; the Pliocene Yinggehai Formation $\left(\mathrm{N}_{2} \mathrm{y}\right)$; and the Quaternary Ledong Formation (Qld) (Figure 2). The Yacheng Formation and Lingshui Formation comprise carbonaceous mudstones and coal seams formed in semienclosed shallow sea and delta front.

The Sanya Formation can be divided into two members: the first member $\left(\mathrm{N}_{1} \mathrm{~s}^{1}\right)$ is mainly interbedded with sandstone and mudstone, and the second member $\left(\mathrm{N}_{1} \mathrm{~s}^{2}\right)$ composed of sandstones intercalated with thin mudstone. The Meishan Formation is composed of argillaceous siltstone and gray mudstone deposited in shallow to semi-deep sea environments, and it also contains submarine fan sandstone. The Huangliu Formation is further divided into two members. The first member $\left(\mathrm{N}_{1} \mathrm{~h}^{1}\right)$ interbedded argillaceous silt- stone and silty mudstone, and the second member $\left(\mathrm{N}_{1} \mathrm{~h}^{2}\right)$ contains gray mudstone and fine sandstone. The Yinggehai Formation is dominated by siltstone and gray mudstone of semideep sea and delta deposition. The Ledong Formation contains shallow marine deposits, and the lithology is mainly gray clay and sandy conglomerates.

The marine mudstone of the $\mathrm{N}_{1} \mathrm{~s}$ and $\mathrm{N}_{1} \mathrm{~m}$ formations are rich in type III kerogen, which is the dominant source rock in the Yinggehai Basin [37]. Multiple sets of reservoirs were developed in the overlying $\mathrm{N}_{1} \mathrm{~h}, \mathrm{~N}_{2} \mathrm{y}$, and Qld formations. The $\mathrm{N}_{2} \mathrm{y}^{2}$ to Qld formations belong to shallow assemblages, the burial depth is relatively shallow, and the pressure coefficient ranges from 1.0 to 1.5 . The $\mathrm{N}_{1} \mathrm{~m}$ to $\mathrm{N}_{1} \mathrm{~h}$ formations are deep buried assemblages, the temperature gradient is more than $45^{\circ} \mathrm{C} / \mathrm{km}$, and the pressure coefficient exceeds 1.8 .

The gravity flow sediments and submarine fan sandstones in the $\mathrm{N}_{1} \mathrm{~h}$ and $\mathrm{N}_{1} \mathrm{~m}$ formations are the main gas reservoirs and are overlain by the thick mudstone of the $\mathrm{N}_{1} \mathrm{y}^{2}$ in the LD-B Wellblock. The dextral strike-slip tensional faults and fractures provide the migration pathway for natural gas in the area, forming a large HTHP lithological gas reservoir [35].

\section{Data and Method}

3.1. Data Source. The accuracy of the modular formation dynamics tester (MDT) pressure is affected by many factors, such as the lithology and permeability of the formation, borehole conditions, and mud properties. In most cases, trustless data are shown in the form of seat sealing failure, superpressure, and dry tests. The mobility (the ratio of permeability and viscosity) was chosen as a key factor to determine the validity of the MDT results, and the relative values of mobility corresponding to the effective points, low-permeability points, and dry points were $1 \sim 20 \mathrm{md} / \mathrm{cp}, 0.01 \sim 0.5 \mathrm{md} / \mathrm{cp}$, and lower than $0.01 \mathrm{md} / \mathrm{cp}$, respectively. Finally, total of 269 points, including 63 effective points, 82 low-permeability points, 59 dry points, 60 sealing failure points, and 5 superpressure points, were classified; only the effective points can be used for pore pressure analysis.

The final shut-in pressure recorded by the drilling stem test (DST) is close to the original formation pressure when the shut-in time is sufficiently long, and the permeability of the formation is high enough. In addition to the depressurization caused by gas development, the shut-in pressure is often affected by factors such as inherently low permeability of formations, incomplete pressure recovery, and local mud-cake problems, so the shut-in pressure cannot be used to reflect the pore pressure directly. Therefore, the measured pressure data need to be screened to determine whether DST data are acceptable [39]. DST has rarely been performed in the LD-B Wellblock, and only 5 effective DST points were selected.

Although the mud weight is not an accurate representation of pore pressure, when balanced or underbalanced drilling technology is used, the mud weight can be a proxy for pore pressure calibrated by the measured pressure [39]. The 


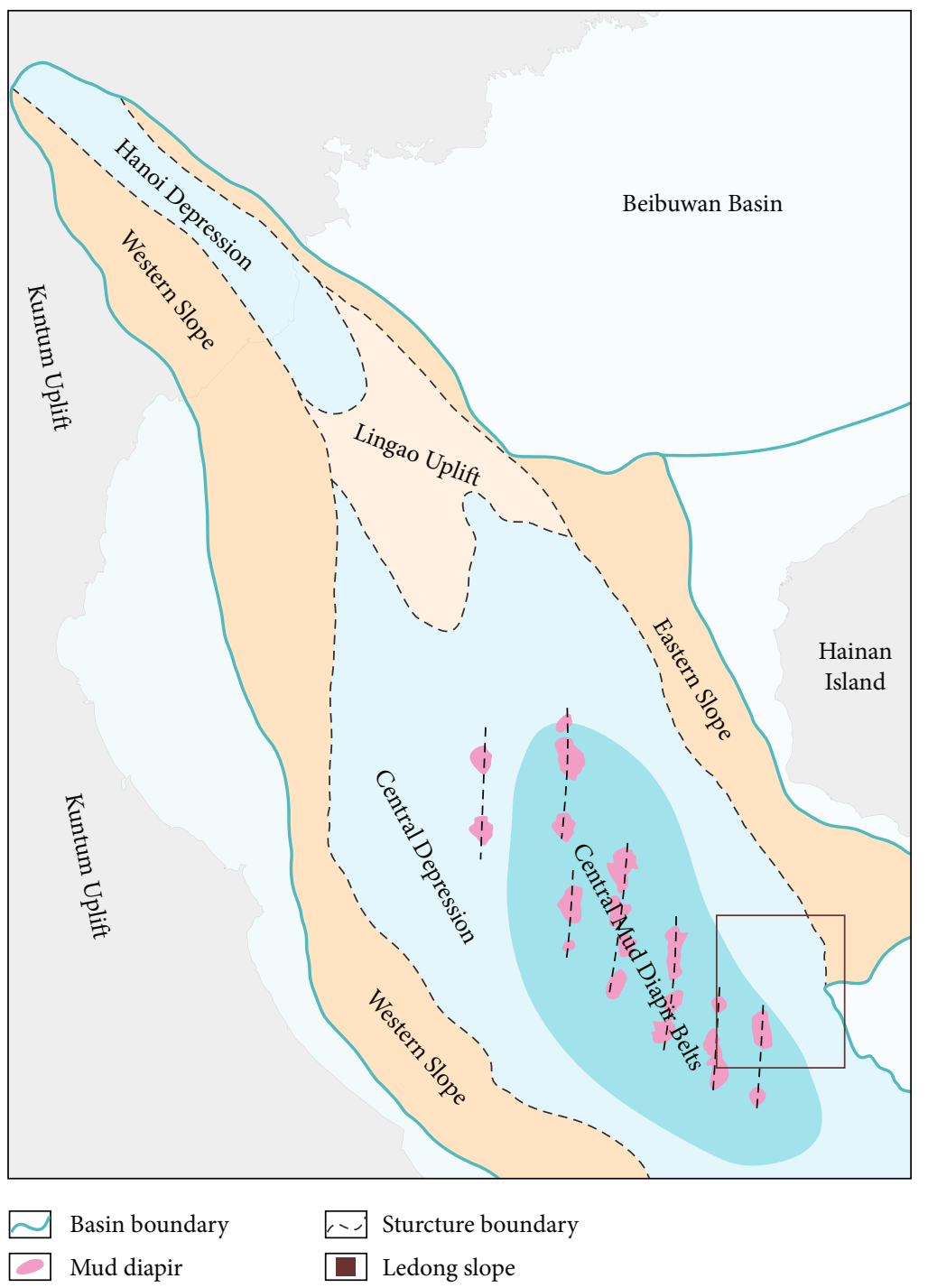

(a)

Figure 1: Continued. 


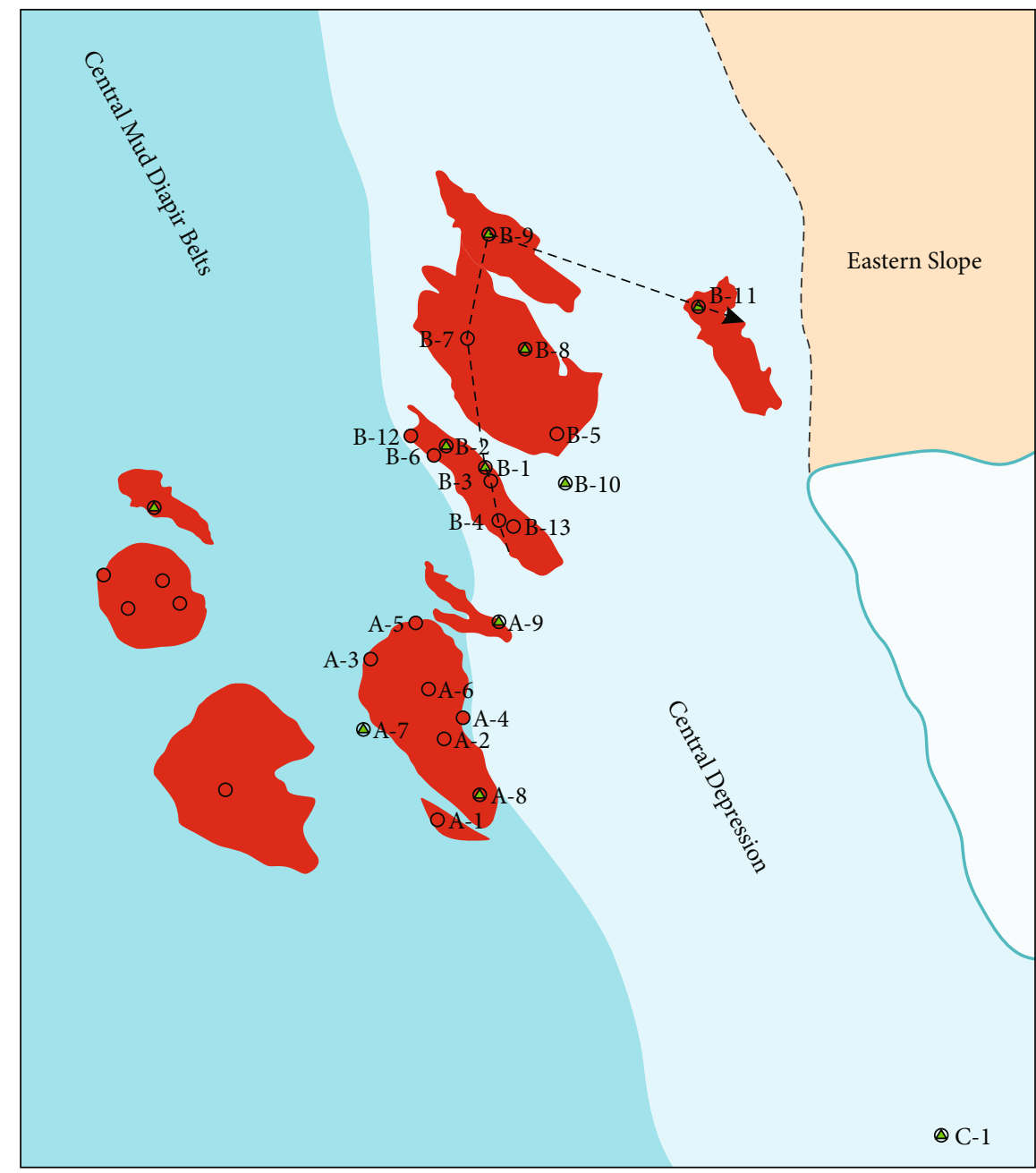

\begin{tabular}{|lll}
\hline & Gas well & Oil-Gas well \\
\hline Gas field & Cross section
\end{tabular}

(b)

FIGURE 1: (a) Simplified structural map of the Yinggehai Basin and the study area, and (b) the distribution of wells in the LD-B Wellblock.

mud weights from more than 20 wells in LD-B Wellblock are selected and converted into equivalent pressures.

By comparing the pore pressure from different sources at similar depths, the MDT pressures are in good agreement with the pressures from DST or mud weight equivalent pressures at corresponding depths (Figure 3 ). This shows that the measured data can reliably reflect the characteristics of underground pressure after screening.

The carbon isotope of the methane $\left(C_{1}\right)$, ethane $\left(C_{2}\right)$ in natural gas, and the carbon dioxide $\left(\mathrm{CO}_{2}\right)$ was measured using SP3400 gas chromatography-combustion-isotope ratio MAT252 mass spectrometer (GC-CIRMS). The carbon isotopic data of the source rocks were derived from Huang et al. [37]. The discrimination plot of different organic gases using $\delta^{13} \mathrm{C}_{1}-\delta^{13} \mathrm{C}_{2}-\delta^{13} \mathrm{C}_{3}$ of natural gas samples was modified from [40].

As the most widely used method for studying the stages of hydrocarbon accumulation, fluid inclusions also record good geohistorical information, which can effectively deter- mine the fluid properties at the time of accumulation. The homogenization temperature is a minimum trapping temperature of fluid inclusions and represents the minimum precipitation temperature of the host mineral. Homogenization temperature measurement of fluid inclusions was carried by Shui et al. [41], using a calibrated Linkam THMSG-600 heating-freezing stage.

3.2. Loading-Unloading Crossplot. The curve reflecting the sonic velocity changes with the increase in the vertical effective stress during the compaction of mudstone is called the loading curve. The unloading effect refers to the decreasing process of the vertical effective stress, and the unloading curve reflects the relationship between the vertical effective stress and the sonic velocity [18]. The loading and unloading curve of mudstone can be used not only to identify the overpressure mechanisms but also to predict pore pressure.

Disequilibrium compaction impedes the process of mudstone compaction, so the vertical effective stress and sonic 


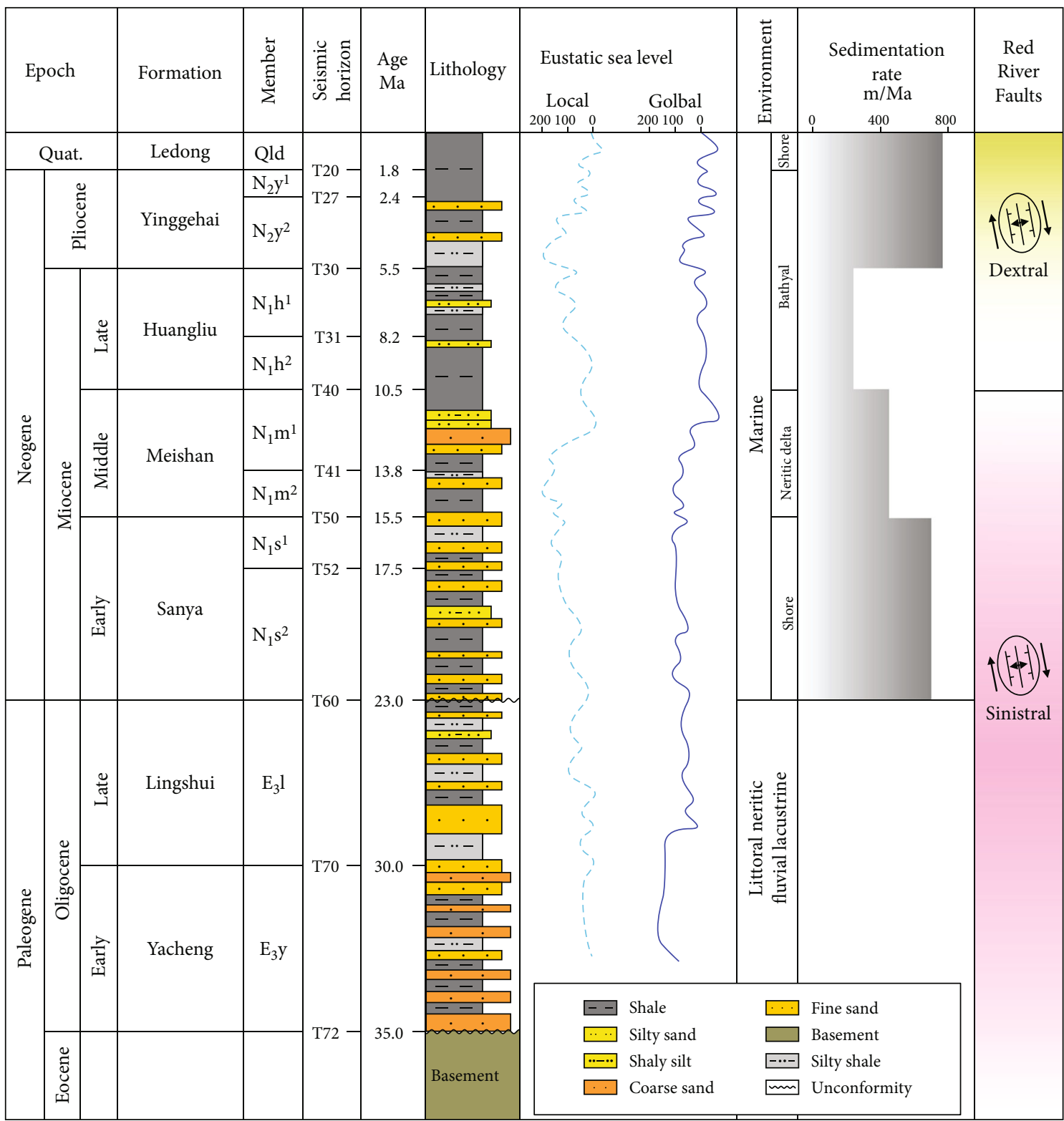

FIGURE 2: The generalized stratigraphic section of the Yinggehai Basin, showing the formations and symbols, seismic horizons, main lithology, and sedimentary environment (modified from [38]).

velocity remain on the loading curve (Figure 4(a)). The vertical effective stress can be calculated corresponding to the given mudstone sonic velocity based on the loading equation. Overpressure caused by fluid expansion or vertical transfer can significantly reduce sonic velocity and vertical effective stress and plots on the unloading curve (Figure 4(b)). Similarly, when the unloading equation is determined, the vertical effective stress can be determined based on the sonic velocity. Furthermore, it is easy to obtain the pore pressure according to the principle of effective stress, that is, the difference between the vertical stress and vertical effective stress.

The loading curve constructed by the relationship between the sonic velocity and vertical effective stress of mudstone can be expressed as follows [18]:

$$
V=V_{0}+A \sigma_{e}^{B},
$$

where $V$ is the sonic velocity of mudstone, $\mathrm{ft} / \mathrm{s} ; V_{0}$ is the sonic velocity of the surface or mudline, generally in $5000 \mathrm{ft} / \mathrm{s} ; \sigma_{e}$ is the vertical effective stress, $\mathrm{MPa}$; and $A$ and $B$ are correlation coefficients, which can be determined by the regression of the vertical effective stress versus the sonic velocity from adjacent wells.

Furthermore, the pore pressure related to the loading mechanism can be calculated by the following formula:

$$
P_{l o}=\sigma_{v}-\left(\frac{V-V_{0}}{A}\right)^{1 / B}
$$

where $P_{l o}$ is the pore pressure in the loading case, MPa; and $\sigma_{v}$ is vertical stress, MPa, which is calculated by integrating the density value. 


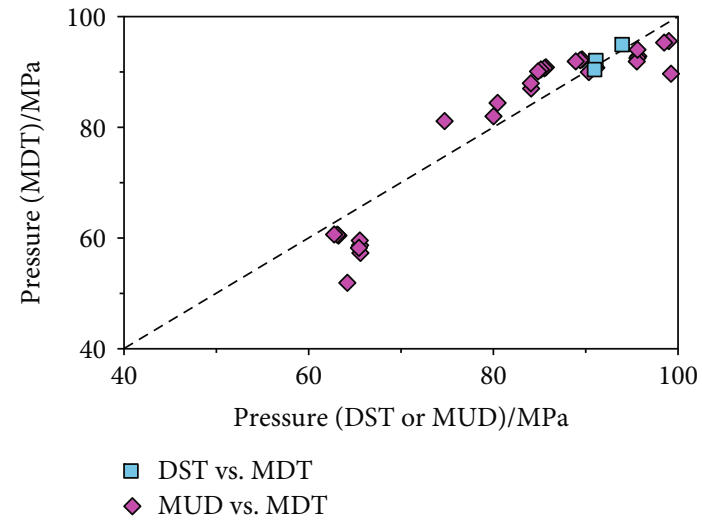

Figure 3: Comparison of pore pressures from different data source. The measured pressure is from the DST and MDT, and MUD means the equivalent pressures calculated from mud weights.

The unloading curve can be described by the following equation [18]:

$$
V=V_{0}+A\left[\sigma_{\max }\left(\frac{\sigma_{\mathrm{v}}}{\sigma_{\max }}\right)^{1 / U}\right]^{B},
$$

where $\sigma_{\max }$ is the maximum vertical effective stress, MPa; $A$ and $B$ are consistent with the parameters of the loading curve; and $U$ is the elastoplastic coefficient of mudstone.

$\sigma_{\max }$ usually equals the vertical effective stress value corresponding to the maximum sonic velocity $\left(V_{\max }\right)$, and $V_{\max }$ is usually equal to the velocity at the start of the velocity reversal.

$U=1$ indicates complete elastic deformation of mudstone, that is, the unloading curve coincides with the original loading curve. $U=\infty$ represents complete plastic deformation. The value of $U$ generally ranges from 3 to 8 with a light local change [11].

The pore pressure can be predicted for the unloading case by the following formula:

$$
P_{u l o}=\sigma_{\mathrm{v}}-\left(\frac{V-V_{0}}{A}\right)^{U / B}\left(\sigma_{\max }\right)^{1-U}
$$

where $P_{u l o}$ is the pore pressure in the unloading case, MPa.

3.3. 1-D Basin Modeling. The 1-D basin modeling is constructed using Schlumberger's PetroMod v2012 to determine the overpressure mechanisms and recover the thermal history. For 1-D modeling, the informations of each unit, including the names, top depth, and thickness, are obtained from the well reports, and the ages are determined from the known ages of the key layers. The mixed lithology of each layer is determined based on cutting descriptions and $V_{s h}$ (mudstone content, which is calculated from gamma-ray logging). The kerogen type, total organic content (TOC), and hydrogen index (HI) are determined based on published data in [42]. Burnham-III kinetics are selected to model hydrocarbon generation, and EASY\% Ro is used to restore the maturity evolution of the source rock. The paleo-water depth
(PWD), sediment-water interface temperature (SWIT), paleo-temperature gradient (PTG), and paleo-heat flow (PHF) used in the 1-D modeling refer to [43].

Regarding the reconstruction of thermal and maturity histories, the vitrinite reflectance and temperatures in holes were used for calibration purposes. Based on thermal evolution history, combined with the homogenization temperature of fluid inclusions, the charging time of natural gas is determined. Based on the burial history, temperature, and maturity evolution simulation results, the pore pressure coupled with the disequilibrium compaction and hydrocarbon generation is modeled. The final modeled pressure is constrained by the measured pressure data and mud weights.

\section{Overpressure Development within the Reservoir}

The screened measured pressure from the MDT and DST and the equivalent pressure are used to analyze the pore pressure characteristics in different reservoirs in the LD-B Wellblock. Overpressure means that the pressure coefficient (ratio of pore pressure and hydrostatic pressure) exceeds 1.2 in this paper.

All the measured pressures in the LD-B Wellblock are overpressures, and the pressure coefficient is between 1.2 and 2.3. The pressure distribution is extremely complicated, the pressure coefficient does not increase with burial depth, and the pressures at different depths and layers are quite different (Figure 5).

Mild-moderate magnitude overpressure developed in $\mathrm{N}_{1} \mathrm{~h}^{1}$ and $\mathrm{N}_{1} \mathrm{~h}^{2}$ above $3950 \mathrm{~m}$, the pressure coefficient ranged from 1.29 to 1.60 , and the excess pressure was approximately 10.65 23.46 MPa. For depths of 3950-4500 m, high-magnitude overpressure (pressure coefficient $>1.6$ ) was observed in the $\mathrm{N}_{1} \mathrm{~h}$ and $\mathrm{N}_{1} \mathrm{~m}$ formations. The pressure coefficient suddenly increased to 2.05-2.27, which is basically close to the fracture pressure gradient, and the excess pressure was between 41.15 and $51.84 \mathrm{MPa}$. The pressure coefficient of $\mathrm{N}_{1} \mathrm{~s}$ in well B-11 at about $4700 \mathrm{~m}$ decreased back to 1.72 , and the excess pressure was $32.78 \mathrm{MPa}$ (Figure 5).

The lateral and vertical features of pore pressure in the LD-B Wellblock are analyzed based on the measured pressures and mud weight equivalent pressures. Overall, the overpressure in the LD-B Wellblock began to develop from the $\mathrm{N}_{1} \mathrm{y}$ formation, and the overpressure top was approximately $2000 \mathrm{~m}$ (Figure 6). The pore pressure varies significantly in different wells vertically. The pore pressure in well B-11 shows a gradual increase, and there is no sudden pressure change. The measured pressure is close to the mud weight equivalent pressure. However, the pore pressure distribution in well B-7 is quite different, the pressure coefficient gradually increases to 1.6 in $\mathrm{N}_{1} \mathrm{~h}^{1}$, and it rapidly increases to about 2.27 in $\mathrm{N}_{1} \mathrm{~h}^{2}$ within only 200 meters. The sudden increase in pore pressure is clearly reflected in the change in the mud weight (Figure 6).

\section{Logging Response to the Presence of Overpressure}

5.1. Sonic and Density Response to Overpressure. The comparison of sonic transit time (AC), which reflects transport 


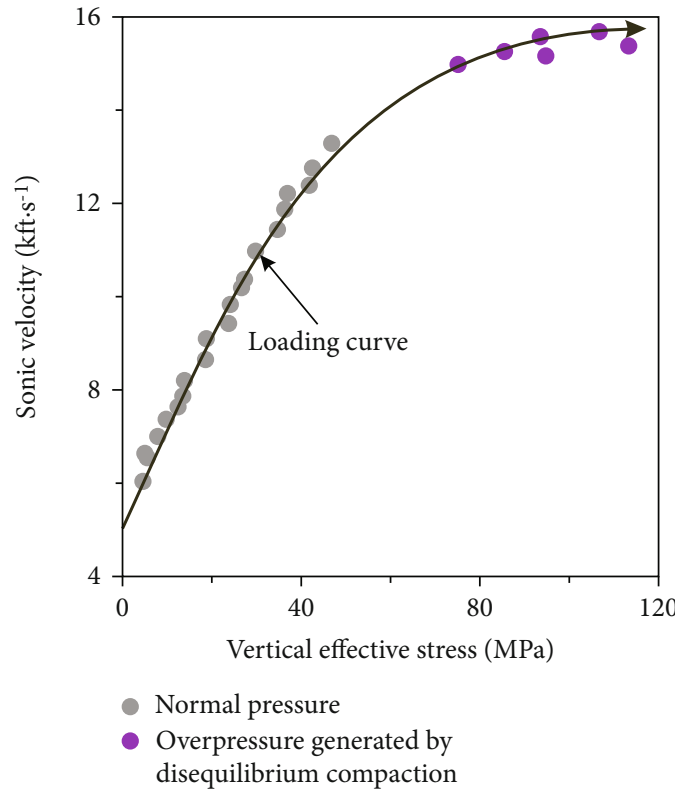

(a)

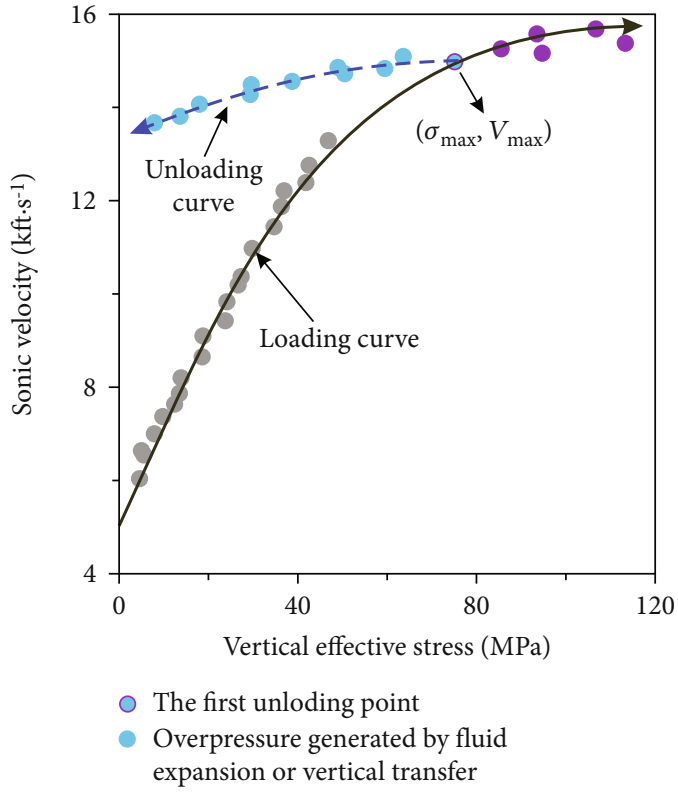

(b)

FIGURE 4: Loading-unloading curve of mudstone constructed by the vertical effective stress and sonic velocity and the identification of overpressure mechanisms (modified from [18]).

properties, with density (DEN), which reflects bulk properties, is helpful for identifying the existence and origin of overpressure. The disequilibrium compaction overpressure shows that both AC and DEN deviate from the normal compaction trend (NCT), while fluid expansion is distinguished by more reversals of AC than that of DEN [20].

Well C-1 is taken as an example to discuss the mudstone compaction response to overpressure. The completion depth of well C-1 is about $5026 \mathrm{~m}$, which corresponds to N1m. The measured pressure data are absent in this well, but continuous mud weights are available. The mud weight equivalent pressure shows that the pore pressure is normal above $3000 \mathrm{~m}$. The overpressure gradually increases with depth over $3000 \mathrm{~m}$, and the mud weight reaches 1.8-2.0 in the deep layer $(>4000 \mathrm{~m})$. The sonic transit time and density of mudstone in the normal pressure section above $3000 \mathrm{~m}$ have a good trend with increasing depth that conforms to the normal compaction trend (Figure 7).

Compared with the normal compaction trend, the sonic transit time of mudstone in the overpressure section deeper than $3000 \mathrm{~m}$ shows abnormally high values, but the density shows only a small deviation. Both the sonic transit time and the density deviate from the normal compaction trend for the overpressure intervals with burial depths exceeding $3500 \mathrm{~m}$. At the top of the overpressure, there is an obvious response to the sonic transit time, but the density response is relatively lagging. The ratio of smectite to illite in the mixed-layer illite/smectite in mudstone decreases gradually within this depth [44], which indicates the chemical compaction. Chemical compaction of mudstone increases the density of mudstone and weakens the logging response to low-magnitude overpressure to a certain extent [45]. When the overpressure is much higher at deeper depths, the density begins to show anomalies, but the amplitude is lower than the sonic transit time (Figure 7). In short, compared with the normal pressure section, the deviation of $\mathrm{AC}$ and DEN from the normal compaction trend can be used as an index of overpressure in the LD-B Wellblock.

5.2. Vertical Effective Stress-Logging Properties. The loadingunloading curves constructed by the vertical effective stress and logging response can be used to effectively distinguish the overpressure mechanisms in sandstone. If the overpressure points fall on the loading curve, it indicates that the overpressure is mainly generated by disequilibrium compaction of mudstone. If the overpressure points deviate from the loading curve, it can be considered the unloading overpressure mechanism, including aquathermal pressurization, hydrocarbon generation, and overpressure transfer [20,46].

The rocks will enter the brittle or even plastic stage in the HTHP environment and possibly change the loading and unloading behaviors [47]. According to the previous studies, the critical condition from the brittle to brittle-ductile transition of the Miocene formations is $32 \mathrm{MPa}$, the corresponding depth is approximately $2500 \mathrm{~m}$, the critical stress from the brittle-ductile transition to plasticity is $123 \mathrm{MPa}$, and the depth is about $8000 \mathrm{~m}$ [48]. Therefore, almost all the Miocene formations are in the brittle-ductile stage, so the difference in the loading and unloading caused by different deformation behaviors may not be significant in the Ledong Slope.

The vertical stress is calculated by integrating density logging, and the vertical effective stress equals the vertical stress minus the pore pressure. The sonic transit time and density are taken as the average value of the mudstones within the interval of the measured pressure data. The normal pressure data of well C-1 above $3000 \mathrm{~m}$ and the LD-A Wellblock are used to establish the loading curve, which is used as a datum baseline to identify possible overpressure mechanisms in the LD-B Wellblock. 


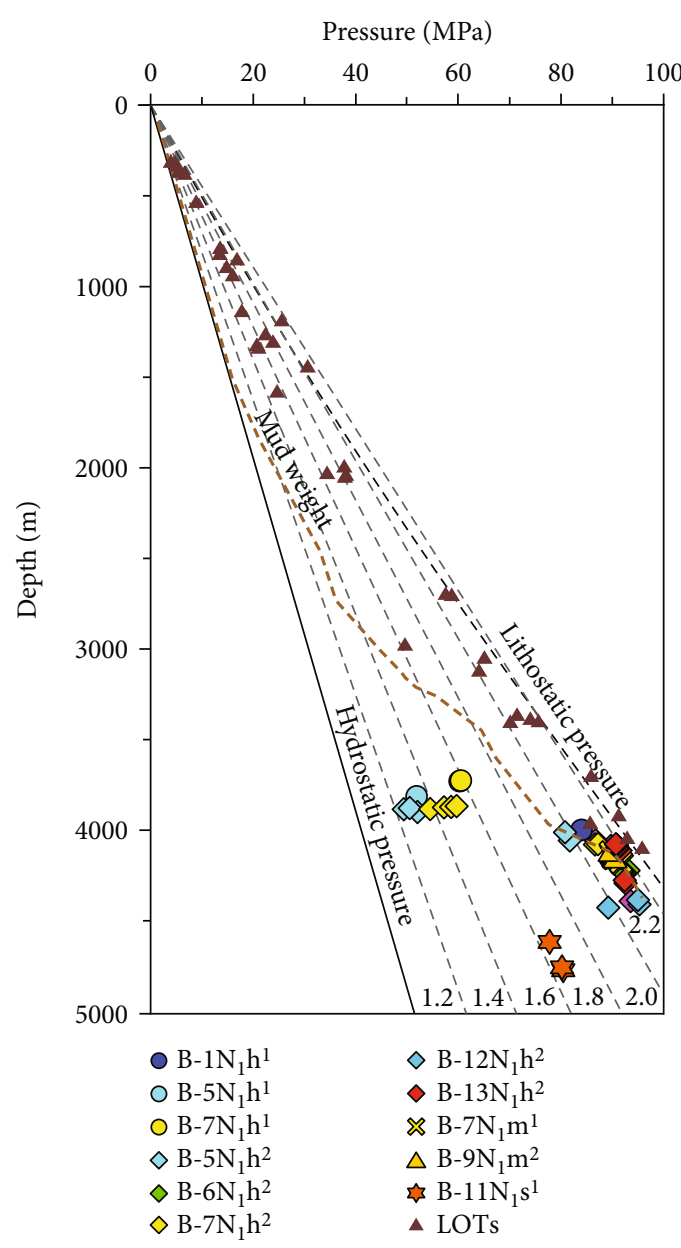

(a)

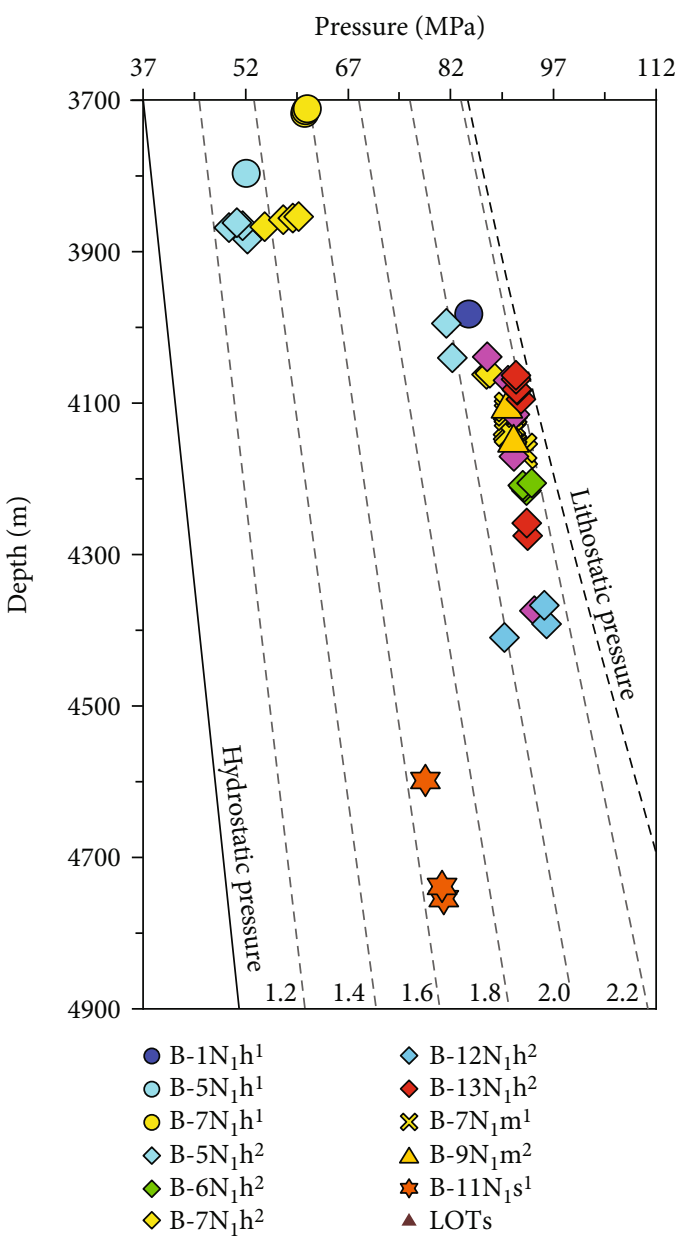

(b)

Figure 5: Pressure in the reservoir versus depth plot of the LD-B Wellblock. Pressure data are from the DST and MDT, and LOTs mean leakoff pressures. (b) is a local enlargement of (a).

The loading-unloading crossplots of the LD-B Wellblock suggest that 10 of the 51 overpressure points plot on the loading curves, and the pressure coefficient is about 1.2-1.6 (Figure 8). The results indicate that the overpressures in sandstone were transmitted from the adjacent mudstone, which is mainly formed by disequilibrium compaction. Notably, the points with pressure coefficients close to 1.51.6 begin to deviate from the loading curve. A key understanding of this study is that all high-magnitude overpressure (pressure coefficient greater than 1.6) points in the LD-B Wellblock deviate the loading curve. With the increase in the pressure coefficient, the corresponding vertical effective stress decreases significantly, and the logging response falls on the unloading curve, while the points on the unloading curve express little or no changes in density, indicating the typical characteristics of unloading overpressure (Figure 8).

\section{Discussions}

6.1. Mechanism of Overpressure Generation. The overpressure sections in LD-B Wellblock show both sonic and density logging response anomalies (Figure 7), indicating the contri- bution of disequilibrium compaction to overpressure. This agrees with the understanding of Luo et al. [15] and Lei et al. [30], and it is also consistent with the results that some overpressure points fall on the loading limb in loadingunloading curves (Figure 8).

Disequilibrium compaction is the most common overpressure mechanism for thick mudstone-dominated successions in continuous rapid burial young basins, which is favored as the mechanism to explain overpressure in a number of basins, including the Yinggehai Basin, Gulf Coast, and North Sea $[15,23,24]$. The geological conditions of the sedimentation in the LD-B Wellblock lead to the occurrence of disequilibrium compaction. The mudstone contents of $\mathrm{N}_{1} \mathrm{~h}$ and $\mathrm{N}_{1} \mathrm{~m}$ in the LD-B Wellblock are approximately $60 \sim 80 \%$, and the deposition rates are greater than $200 \mathrm{~m} / \mathrm{Ma}$, showing the rapid deposition of mud-rich layers. The mudstone content of the overlying $\mathrm{N}_{1} \mathrm{y}$ is more than $85 \%$, the deposition rate reaches $1000 \mathrm{~m} / \mathrm{Ma}$, and the deposition rate of Qld is also over than $500 \mathrm{~m} / \mathrm{Ma}$. Such high sedimentation and burial rate combined with mud-dominated sequences are beneficial to the development of disequilibrium compaction. The numerical simulation results confirm 


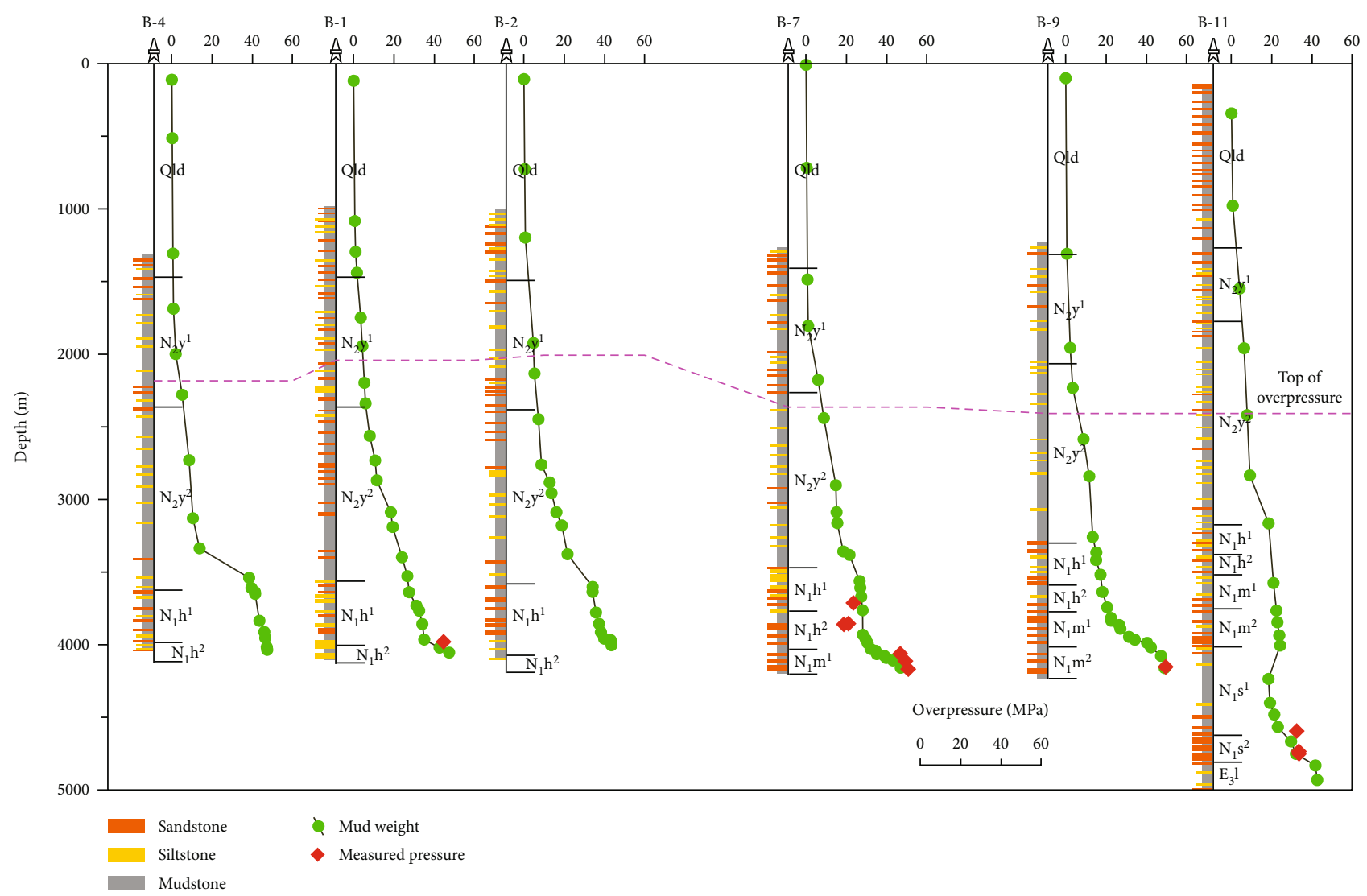

Figure 6: Pore pressure distributions in the LD-B Wellblock, showing the top of the overpressure. The pore pressure was obtained from the MDT, DST, and mud weight. The location of the section is shown in Figure 1(b).

that the pore pressure coefficient can reach approximately 1.5-1.6 due to disequilibrium compaction of mudstone [15, $43]$, which is consistent with the results that the points with pressure coefficients smaller than 1.6 plot on the loading curve (Figure 8).

The amplitude of the sonic transit time deviating from the normal compaction trend in the deep high overpressure section is much larger than that of the density, and the points with pressure coefficients greater than 1.6 fall on the unloading curve. The evidence shows that disequilibrium compaction alone is not enough to generate the high overpressure observed in reservoirs and indicates the contribution of unloading mechanism. In theory, there are four mechanisms leading to unloading effect: aquathermal pressurization, clay diagenesis, gas generation, and overpressure transfer. This paper analyzes these mechanisms in detail and evaluates the possible efficiency of each mechanism through the analysis of regional geology.

Due to the higher temperature gradient, the temperature reaches $180^{\circ} \mathrm{C}$ at a depth of $4000 \mathrm{~m}$ in the LD-B Wellblock, and aquathermal pressurization is considered to be one of the causes of overpressure $[36,49]$. However, quantitative simulation results confirmed that even the permeabilities of rocks were down to $3 \times 10^{-22} \mu \mathrm{m}^{2}$, and the aquathermal pressuring was negligible [50]. In fact, this permeability is much less than the permeabilities of real shales $\left(0.1 \sim 1 \times 10^{-18} \mu \mathrm{m}^{2}\right)[50,51]$. In addition, a high temperature will reduce the viscosity of pore fluid, thereby promoting the dissipation of pore fluid [50]. Therefore, we conclude that significant aquathermal pressurization does not occur in the LD-B Wellblock.

The diagenetic transformation from smectite to illite has been thought to generate overpressure by releasing bound water or load transfer mechanisms [1, 46, 52]. It has been proven that clay diagenesis can generate very slight overpressure through the fluid expansion process [45]. The load transfer process related to clay diagenesis may generate significant overpressure $[46,52]$, especially when the temperature is higher than $90^{\circ} \mathrm{C}$. And the load transfer has been demonstrated in the Gulf of Mexico and North Sea Basin, with suggestions that overpressure of as much as $14 \mathrm{MPa}$ can be generated through this process [25, 26, 52, 53]. However, the biggest difference between the Yinggehai Basin and Gulf of Mexico and North Sea Basin is that the Gulf of Mexico and North Sea Basin are anomalously smectite-rich system $[52,53]$. Small volumes of smectite in mudstones in the LD-B Wellblock have been reported [44], suggesting that the influence of the load transfer effect on overpressure in the LD-B Wellblock is not significant due to the limited transformation of smectite.

Kerogen or oil-to-gas cracking leads to a substantial increase in fluid volume, which may theoretically result in overpressure close to lithostatic pressure $[3,4]$. The gas generation has been proved to be an effective pressurization mechanism in Gulf of Mexico and North Sea Basin [1, 23, 

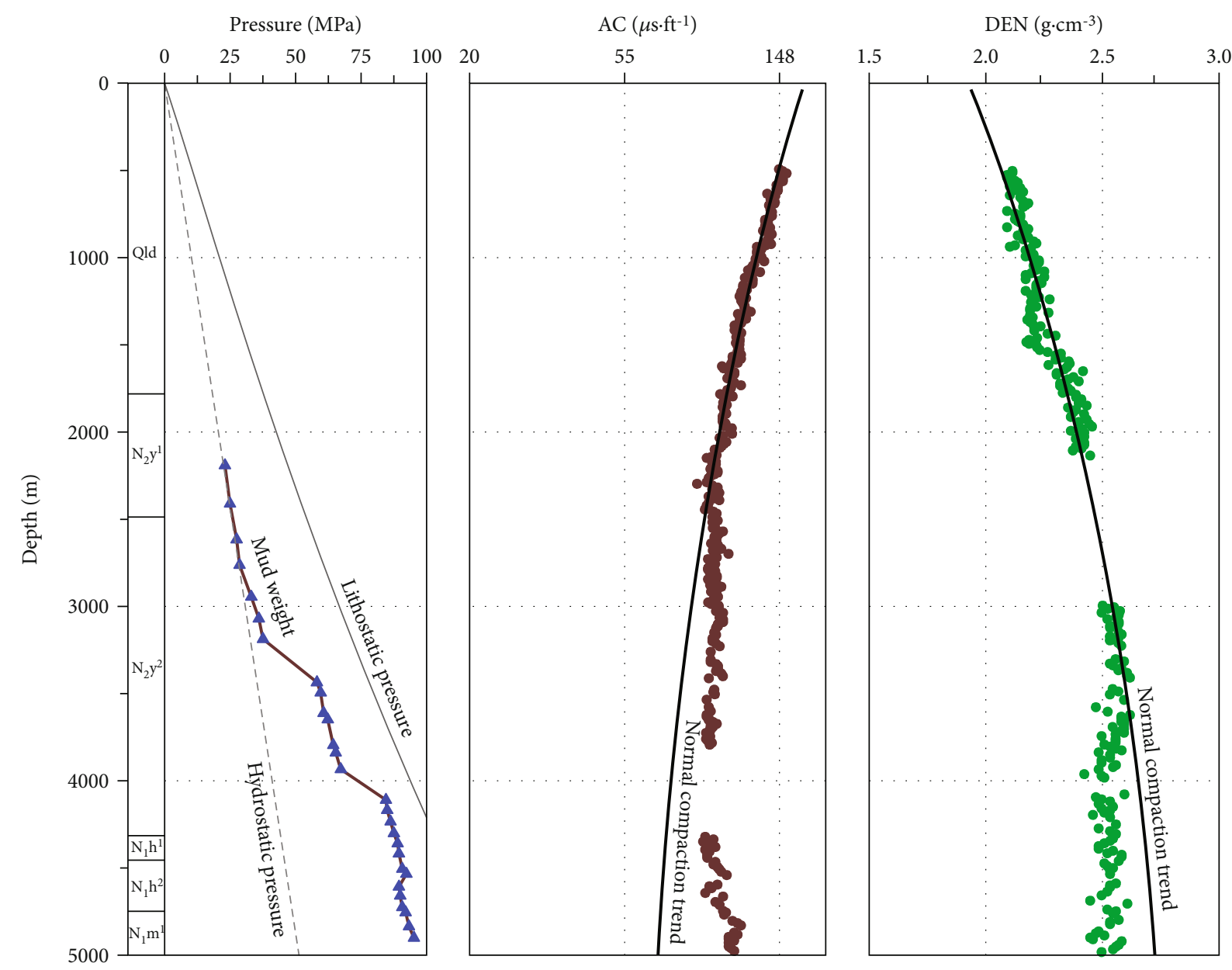

Figure 7: Profiles of sonic transit time, density, and mud weight for well C-1 in the Ledong Slope. The location of the well is shown in Figure 1(b).
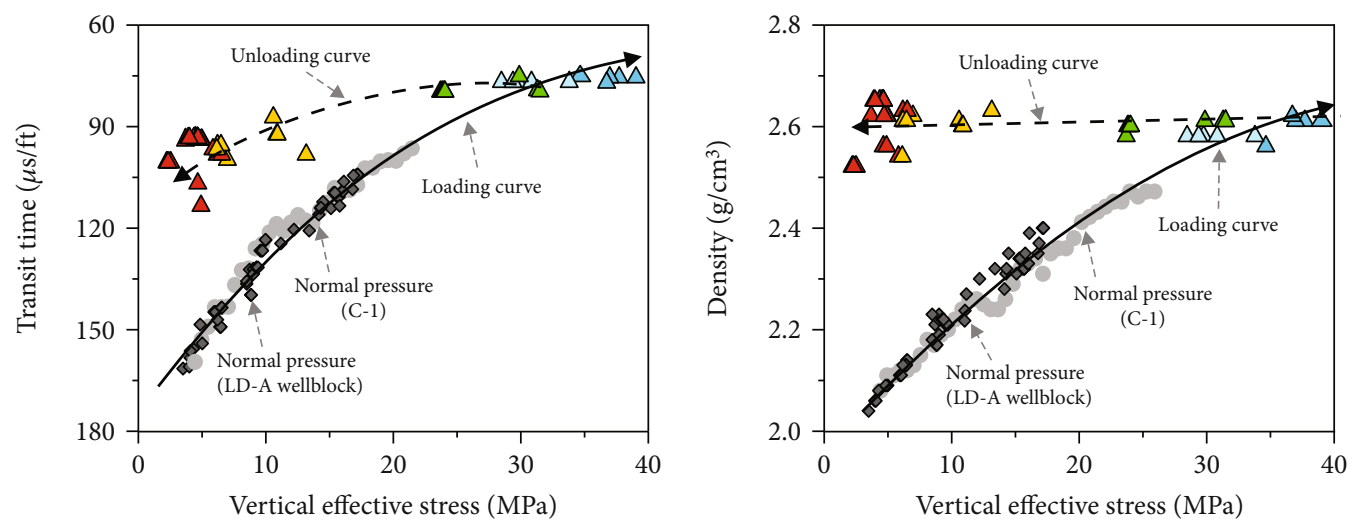
$\Delta$ 1.2-1.4
$\triangle 1.8-2.0$
$\triangle$ 1.4-1.6
$\Delta$ 2.0-2.2
$\Delta$ 1.6-1.8
$\Delta$ 2.2-2.4
$\triangle$ 1.2-1.4
$\triangle 1.8-2.0$
$\triangle$ 1.4-1.6
$\Delta$ 2.0-2.2
$\Delta$ 1.6-1.8
$\Delta$ 2.2-2.4

(a)

(b)

FIGURE 8: (a) Vertical effective stress versus sonic transit time crossplots and (b) vertical effective stress versus density crossplots for the LD-B Wellblock in the Yinggehai Basin. The loading curve is constructed by the normal pressure of well C-1 and the LD-A Wellblock. 


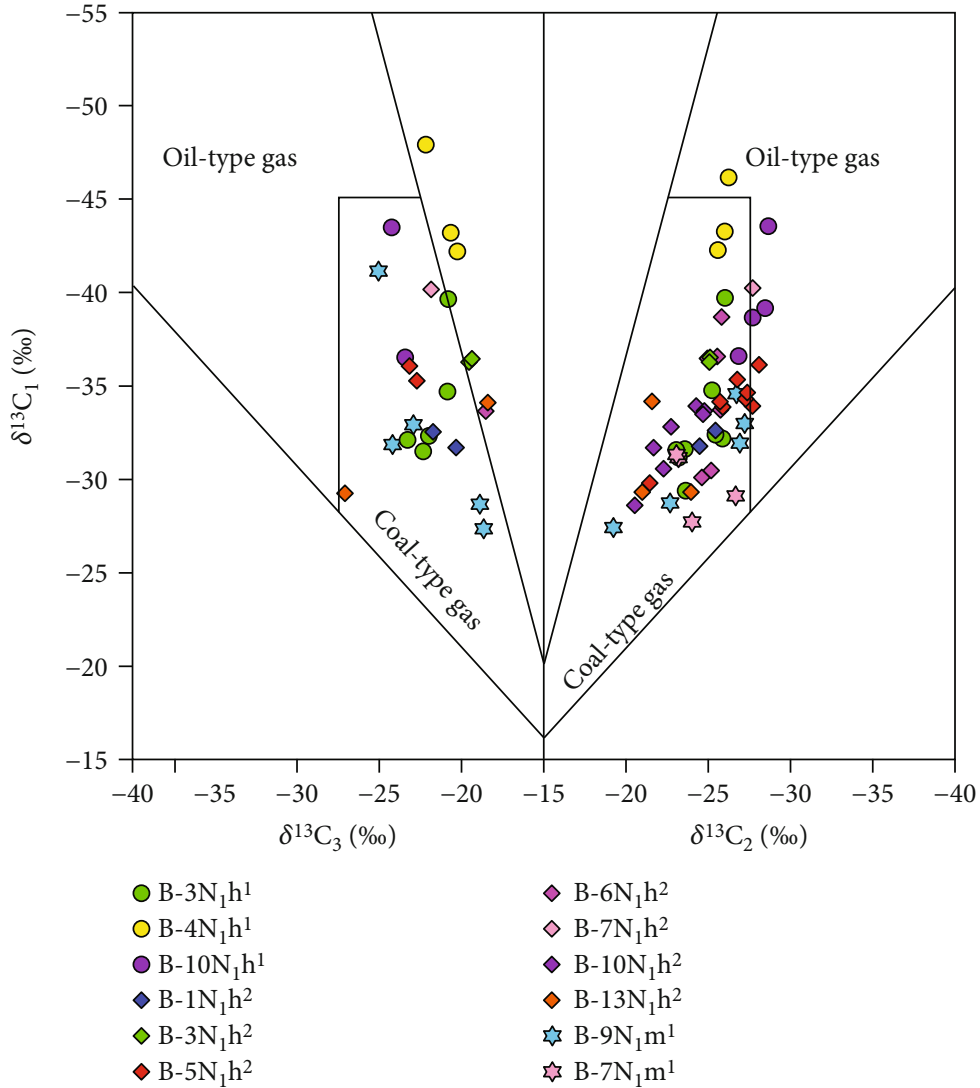

(a)

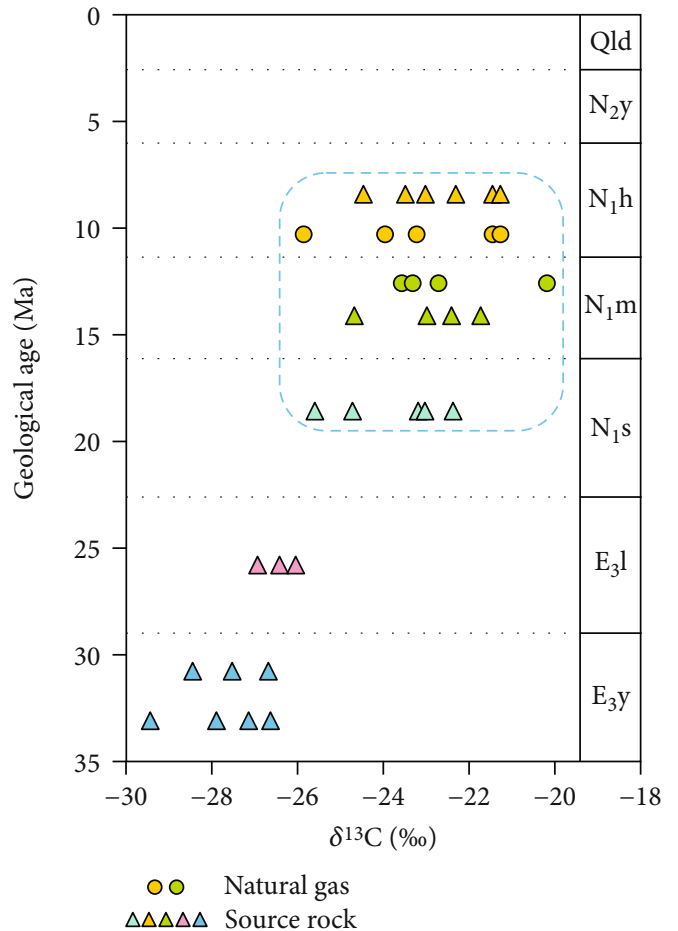

(b)

Figure 9: (a) Genetic classification of natural gas (the discrimination diagram is modified from [40]) and (b) the stable carbon isotope of the natural gas and source rocks in the LD-B Wellblock in the Yinggehai Basin.

24], while it is not in the Yinggehai Basin. The average total organic carbon (TOC) of mudstone in $\mathrm{N}_{1} \mathrm{y}$ and $\mathrm{N}_{1} \mathrm{~h}$ is less than $0.6 \%$, and the TOC of the $\mathrm{N}_{1} \mathrm{~m}$ and $\mathrm{N}_{1}$ s source rocks is about $1.55 \%$. The pore pressure of well C-1 was simulated to quantitatively evaluate the hydrocarbon generation pressurization effect. For Miocene source rocks with burial depths less than $5000 \mathrm{~m}$, liquid hydrocarbon is the dominated product, and gas production is limited. Moreover, oil generation has little effect on overpressure, so the effect of hydrocarbon generation is not an important overpressure mechanism [15]. Obvious gas generation occurs below a depth of $5000 \mathrm{~m}$, and overpressure caused by gas generation in the $\mathrm{N}_{1}$ s source rock is significant, the ratio can exceed $50 \%$ in ultradeep source rocks $[15,43]$.

Even considering the possible self- and neighbor-source overpressure, it is not sufficient to explain some extreme overpressures phenomenon in permeability formations. Thus, some other more effective mechanisms, such as overpressure transfer, must be considered. A common concept used to explain the presence of overpressure within sandstones is that of the centroid, in which lateral pressure from deep overpressured formations transfer through an inclined sandbody to shallow intervals, resulting in a higher pressure in the latter than expected $[13,14]$. The presence of faults/fractures within the overpressure system has the potential to transfer overpressure into shallower formation via enhanced permeability through fault/fracture planes $[7,15$, $17,54]$. The most likely mechanism of high-magnitude overpressure in Miocene reservoirs in the LD-B Wellblock is overpressure vertical transfer along faults/fractures. Previous studies have proposed allo-source overpressure to explain overpressure generation in the Yinggehai Basin. The vertical transfer phenomenon was once thought to occur mainly in the diapir zone of the Yinggehai Basin due to the development of faults, which is easily caused the upward flow of overpressure fluid $[28,29]$. Overpressure is considered to be less susceptible to vertical transfer in nondiapir zones because the faults generally do not develop [28, 31]. Researchers have suggested that the overpressure is mainly caused by disequilibrium compaction and hydrocarbon generation considering the LD-B Wellblock belonging to nondiapir zone $[36,49]$. However, the evidence in this study shows that allo-source overpressure caused by vertical transfer in the nondiapir zone is still an extremely important overpressure mechanism. In fact, there is sufficient geological evidence to support the viewpoint that overpressure in Miocene reservoirs was affected by the transfer process of ultradeep overpressure fluid along faults/fractures.

6.2. Evidence for Overpressure Generation by Vertical Transfer. The pore pressure in Miocene reservoirs in the LD-B Wellblock shows abruptly transition from moderate 


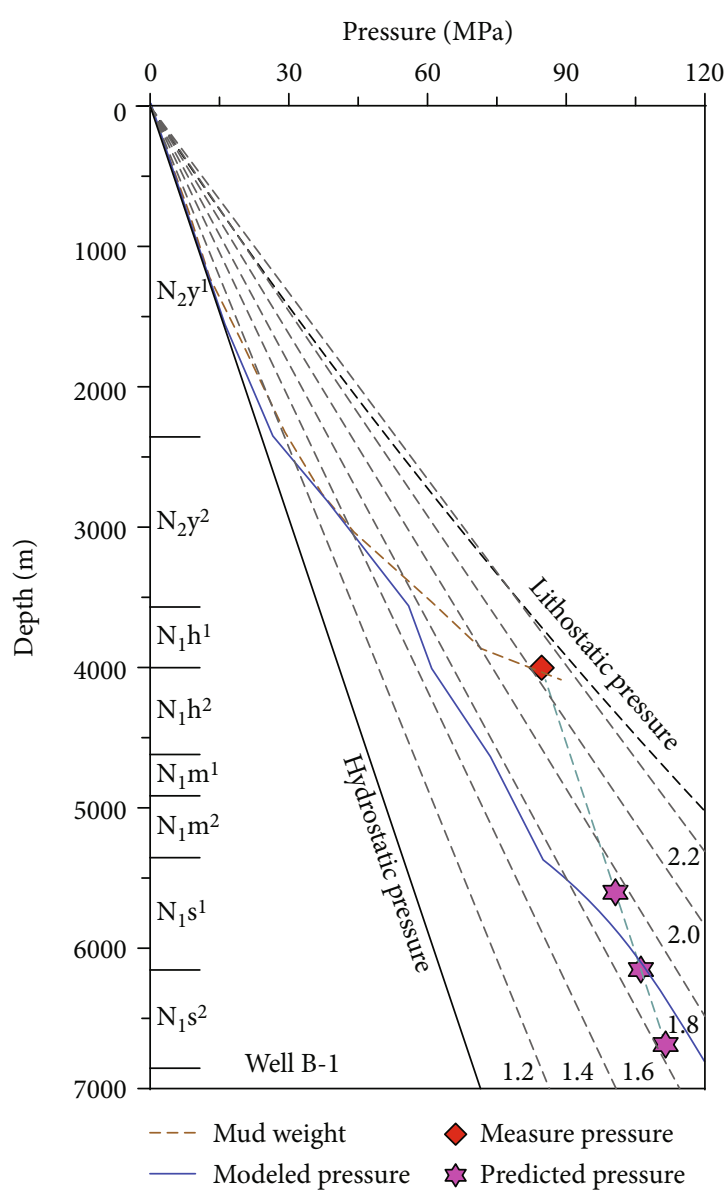

(a)

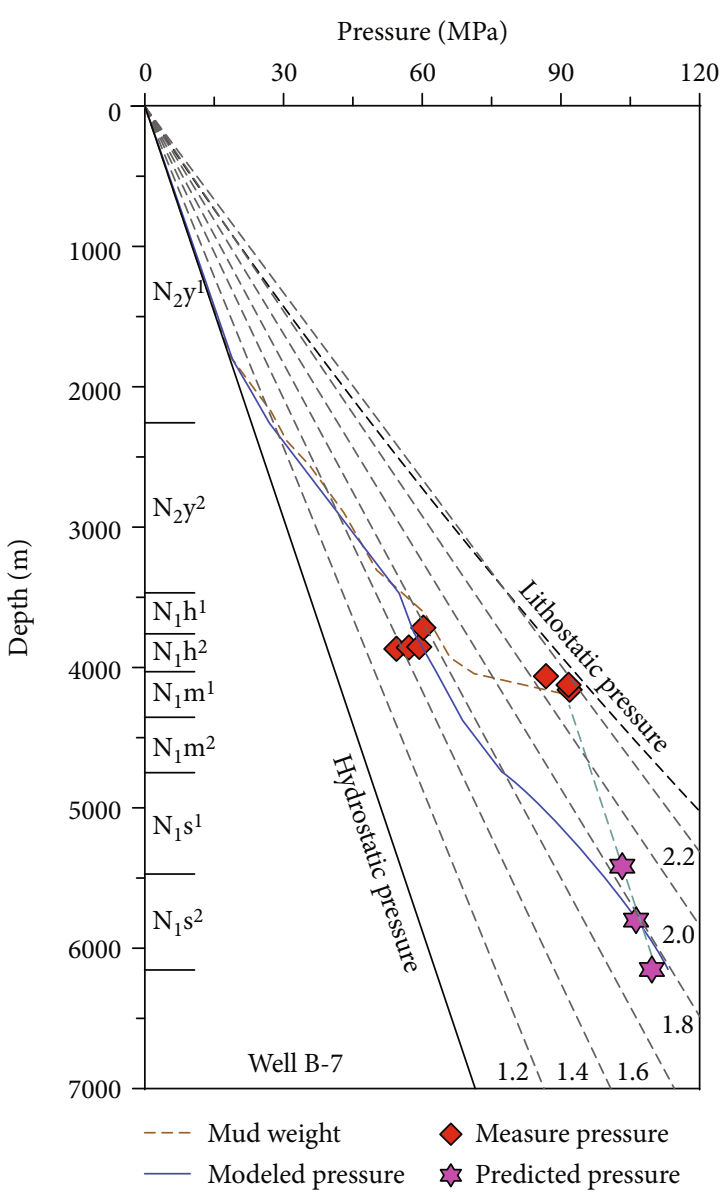

(b)

FIGURE 10: The modeled pressure of the ultradeep buried source rock in the LD-B Wellblock. The stars are the predicted pressure according to the characteristics of the vertical transfer pressure, which is parallel to the hydrostatic pressure. The location of the well is shown in Figure 1(b).

to high-magnitude overpressure, and the vertical effective stress-logging crossplots show a typical unloading response. According to the above analysis, the ratio of overpressure caused by hydrocarbon generation is limited. Therefore, the abrupt pressure transition zone and unloading effect can only be explained by the overpressure vertical transfer. We will carry out a detailed geological analysis to discuss the source of deep overpressure fluid, the transfer pathway of allosource overpressure, and the mode of the overpressure transfer process.

6.2.1. The Fluid Source of Overpressure Transfer. Since the high-magnitude overpressure belongs to allo-source overpressure in reservoirs in the LD-B Wellblock, the source of overpressure coming from deeper away from the Miocene reservoirs. The presence of high-magnitude overpressure in the deep system is prerequisites for this mechanism. The overpressure transfer process in permeable formations is accompanied by fluid migration. Therefore, determining the source of natural gas also indicates clarifying the source of overpressure fluid.

The carbon isotope composition of natural gas is a good indicator to identify its genetic type and source [40]. The $\delta^{13} \mathrm{C}_{1}$ of the gas sample from the $\mathrm{N}_{1} \mathrm{~h}$ reservoir in the LD-B Wellblock is about $-34.04 \%$ o $-29.44 \%$, and the value of $\delta^{13} \mathrm{C}_{2}$ is about $-25.88 \% \sim-23.13 \%$. The $\delta^{13} \mathrm{C}_{1}$ and $\delta^{13} \mathrm{C}_{2}$ of the gas sample from the $\mathrm{N}_{1} \mathrm{~m}$ gas pool are $-29.24 \%$ o $\sim-27.40 \%$ and $-23.13 \%$ $\sim-20.26 \%$, respectively. Both the $\delta^{13} \mathrm{C}_{2}$ values of natural gas in $\mathrm{N}_{1} \mathrm{~h}$ and $\mathrm{N}_{1} \mathrm{~m}$ are greater than $28 \%$, indicating typical characteristics of natural gas generated from coal-bearing source rocks. The $\delta^{13} C_{1}-\delta^{13} C_{2}$ diagram of natural gas shows that almost all gas samples from the LD-B Wellblock plot in the coal-type gas area (Figure 9(a)).

The mudstones of $\mathrm{E}_{1} \mathrm{l}$ and $\mathrm{N}_{1}$ s are two sets of source rocks in the Yinggehai Basin and show greatly different carbon isotope compositions. The $\delta^{13} \mathrm{C}_{2}$ value of kerogen in the $\mathrm{N}_{1} \mathrm{~s}$ source rock is obviously heavier, mainly ranging from $-25 \%$ o to $-21 \%$, with an average of $-23.8 \%$. It is about $-30 \%$ $-26 \%$ with an average of $-27.2 \%$ o for kerogen in the $\mathrm{E}_{1} \mathrm{l}$ source rock [55]. Available data show that the natural gas in the LD-B Wellblock is more closely related to the $\mathrm{N}_{1}$ s source rocks (Figure $9(\mathrm{~b})$ ).

It has been confirmed that the overpressure fluid mainly came from the $\mathrm{N}_{1}$ s source rock, and a 1-D model is established to simulate the overpressure generation of $\mathrm{N}_{1} \mathrm{~s}$. The 


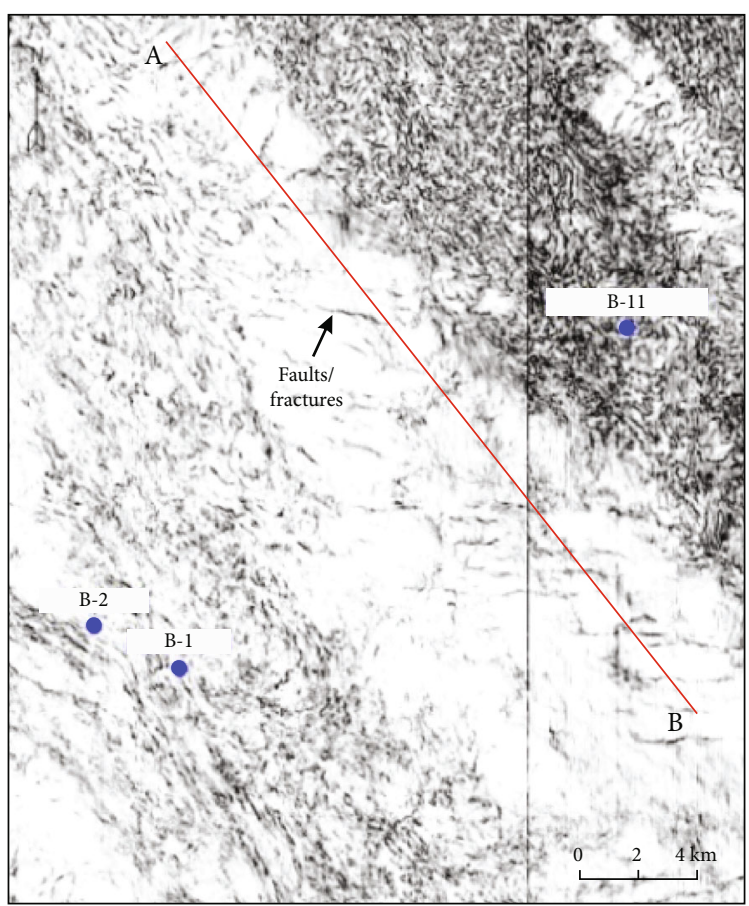

(a)

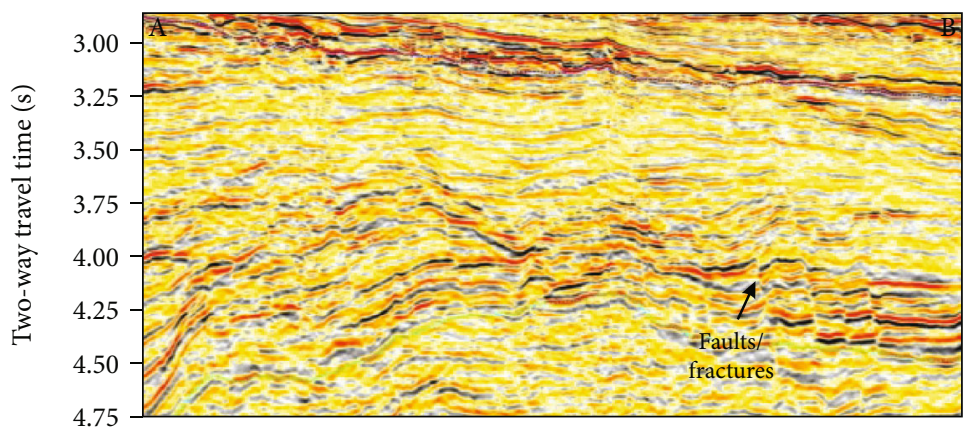

(b)

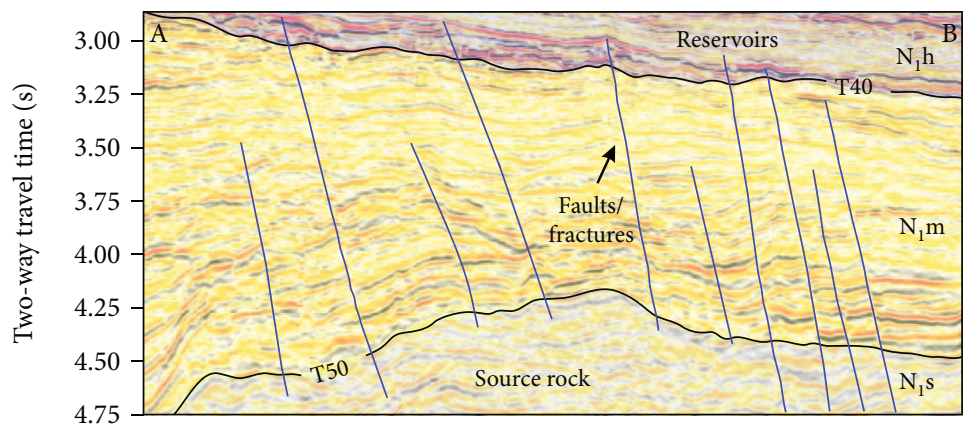

(c)

FIGURE 11: (a) Variance slices of the Ledong Slope in the Yinggehai Basin (4250 ms), note that these extensional faults are primarily oriented E-W, (b) seismic section in two-way travel time showing series of hidden faults or microfractures, and (c) interpretation of the seismic section showing the source rock and reservoirs.

pore pressure of the two wells is restored by coupling disequilibrium compaction and hydrocarbon generation. The modeled pore pressure in the $\mathrm{N}_{1} \mathrm{y}$ and overlying formations is basically consistent with the mud weight equivalent pressure, and the pressure in the permeable formation is similar to that in the adjacent mudstone (Figure 10). The measured pressure in $\mathrm{N}_{1} \mathrm{~h}$ and $\mathrm{N}_{1} \mathrm{~m}$ is larger than that in the simulated result, indicating that the pore pressure is affected by overpressure transfer. The geological conditions of $\mathrm{N}_{1}$ s source rocks are benefit to disequilibrium compaction and substantial gas generation potential, which lead to a significant increase in the pore pressure, and the pressure coefficient of $\mathrm{N}_{1} \mathrm{~s}$ reaches about 1.9-2.0. If the overpressure is affected by vertical transfer, the pressure gradient in sandstones equals to the hydrostatic pressure gradient. The estimated pore pressure in $\mathrm{N}_{1} \mathrm{~s}$ according to the measured pressure in shallow reservoirs is basically close to or slightly lower than the modeled result
(Figure 10), which further confirms that ultradeep buried source rocks have the potential for overpressure transfer.

6.2.2. The Pathway for Overpressure Transfer. Studies on faults in nondiapir zones are very preliminary for a long time due to the limited resolution of seismic data and unobvious fault throw. It is considered that there is a lack of pathways required to form allo-source overpressures in the Ledong Slope. Therefore, the migration pathway of gas from the ultradeep buried Miocene source rocks to the shallower reservoir is a key factor for the formation of allo-source overpressures.

In recent years, three-dimensional seismic coherence and curvature analysis technologies have been applied to obtain a new understanding in the identification of the high-pressure diapir system and the fracture migration system in the Yinggehai Basin [56]. The seismic profile shows that there are a 


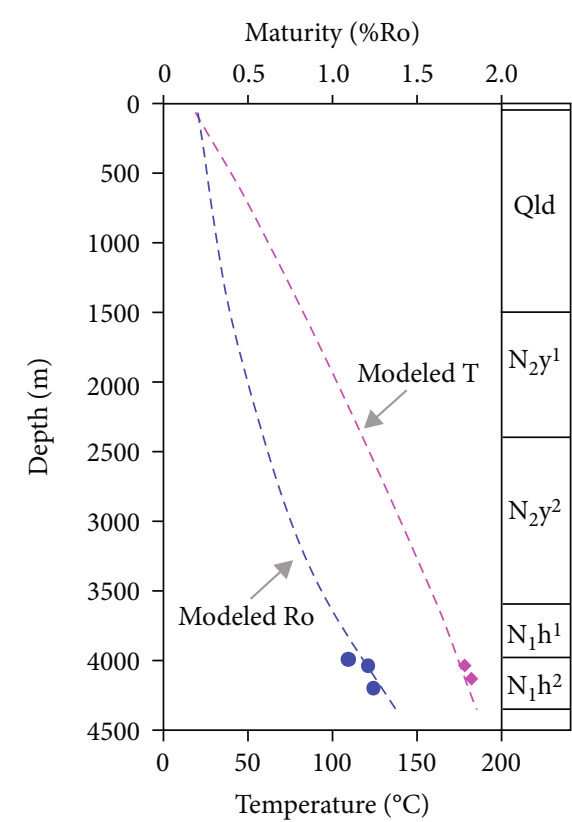

(a)

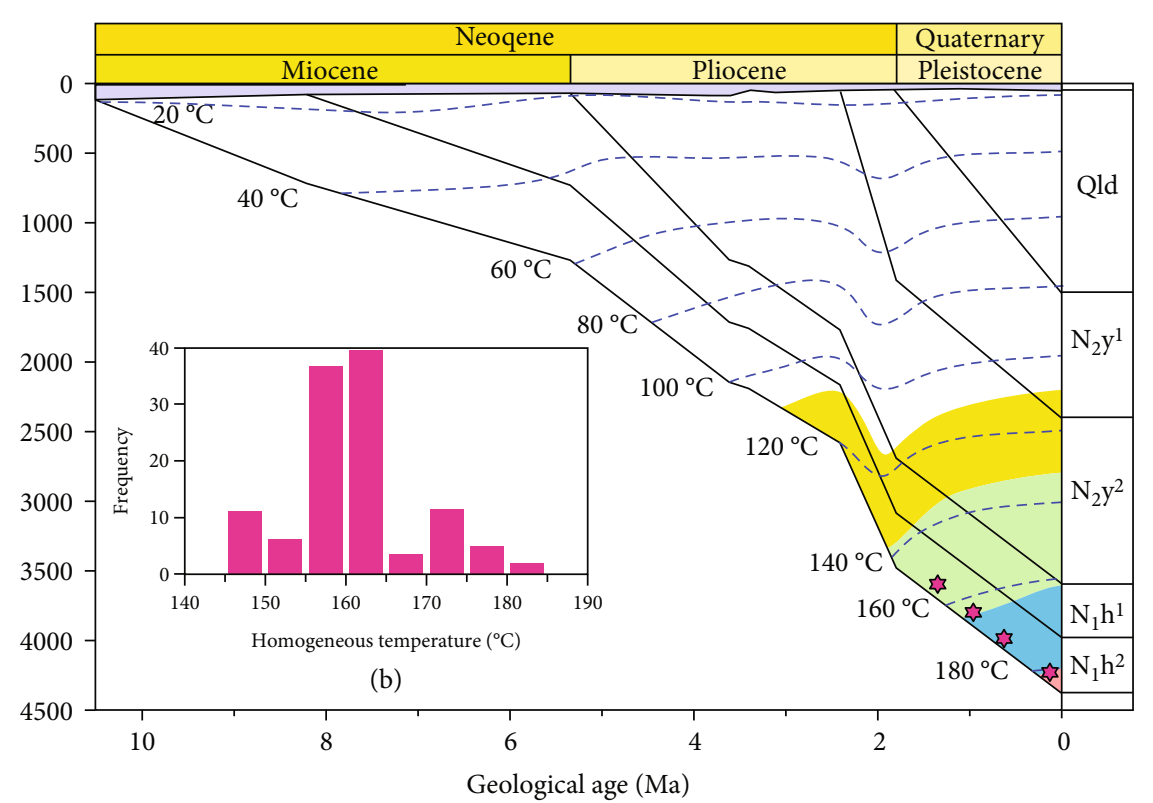

(c)

\footnotetext{
- Measured T

- Measured Ro
}

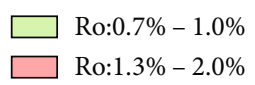

FIGURE 12: The natural gas charging period of the LD-B Wellblock in the Yinggehai Basin. (a) Modeled maturity and temperature with test data calibration, (b) homogeneous temperature of inclusions (modified from [41]), and (c) burial-thermal history and the charging time of natural gas.

series of hidden faults/microfractures with little throw in the Miocene formations that are densely distributed in nearly $\mathrm{E}-\mathrm{W}$ direction (Figure 11(a)), and the faults/microfractures have also been fully verified in the $3 \mathrm{D}$ seismic profiles [35, $55,56]$. The hidden faults or microfractures are mainly developed at $\mathrm{N}_{1} \mathrm{~m}$, extending upward to the bottom of $\mathrm{N} 1 \mathrm{~h}$ (Figures 11(b) and 11(c)).

Although these hidden faults/microfractures stopped extending upward after $10.5 \mathrm{Ma}$ (the time of the base of $\mathrm{N}_{1} \mathrm{~h}$ ), due to the low friction coefficient of existing faults, the faults/microfractures will open when the pore pressure exceeds the failure threshold of incohesive faults [57]. The opening hidden faults/microfractures connect the reservoirs and source rocks, and the deep overpressure natural gas can episodically migrate upward to the reservoirs. The migration and accumulation process of gas will inevitably lead to the vertical transfer of overpressure, resulting in high overpressure in shallower reservoirs.

The overpressure vertical transfer induces the opening faults to close due to the overpressure decreases in the deep reservoirs. The low-fluid diffusion rate of mudstone maintains a higher overpressure than surrounding sandstones [9, 15]. Therefore, fluid in the deep buried system continuously flows from low-permeability mudstones to permeable sandstones during and after fault opening, which leads to an increase in overpressure in sandstones, and eventually facilitates the fault opening for next time. Deeply-buried source rocks generally have enough overpressure fluid to maintain episodic fault opening, which ensures the preservation of high overpressure in shallow formations.
6.2.3. Preservation of Vertically Transferred Overpressure. The overpressuring effects in permeable sandstone are generally instantaneous phenomena, and the overpressure dissipates quickly unless effectively sealed. Generally, the later the faults open, the more effective the sealing, and the longer time for transferred overpressure preservation in sandstone.

The time of source rock maturity in the Ledong Slope is often too late, as is the natural gas charging period. The results of the kinetics of gas generation and carbon isotope fractionation suggested that the gas reservoir in the LD-B Wellblock was formed since $1.2 \sim 0.1 \mathrm{Ma}[37,55]$. The homogenization temperatures of aqueous inclusions formed with simultaneous gas-bearing inclusions are mainly distributed between $155 \sim 165^{\circ} \mathrm{C}$ and $170 \sim 185^{\circ} \mathrm{C}$ in the $\mathrm{N}_{1} \mathrm{~h}$ and $\mathrm{N}_{1} \mathrm{~m}$ reservoirs [41]. The formation age of natural gas pools can be obtained by coupling the homogenization temperatures of the inclusions with the burial-thermal history. The result shows that there is one phase of continuous gas charging in the LD-B Wellblock, and the charging time is approximately1.50 0.2 Ma (Figure 12).

The fault opening is current or geologically recent, which means that the transfer overpressure was formed at $1.50 \mathrm{Ma}$ or even later. The channel sandbodies in the LD-B gas reservoir are deeply buried, the reservoir properties are poor, and the sandbodies are surrounded by overpressure mudstone. The large amount of gas in the reservoir further decreases the rock permeability due to the coexistence of two phases. These comprehensive effects lead to the preservation of transfer overpressure. It has been documented that mudstone of several tens of meters can maintain overpressure in 


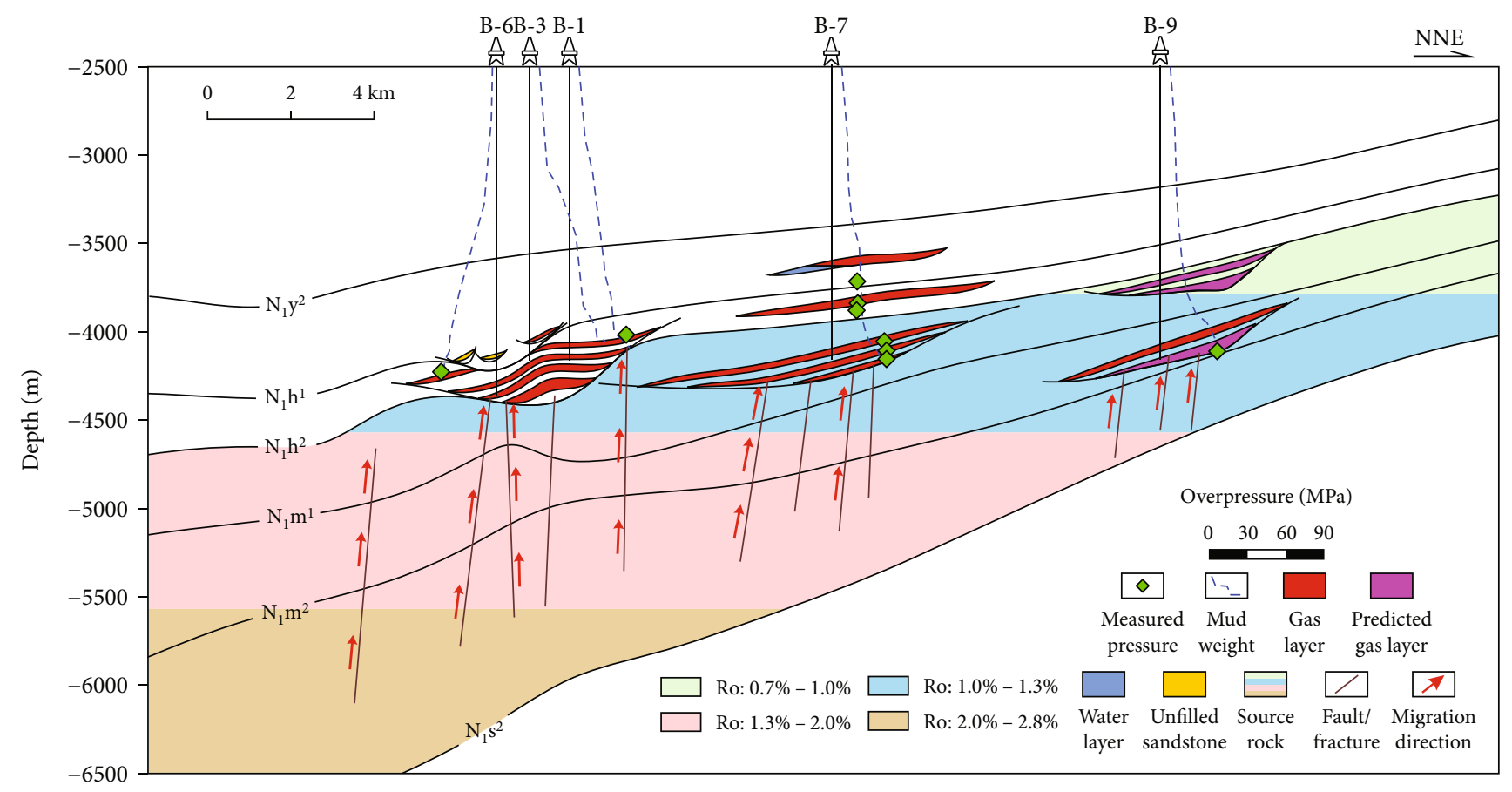

FIGURE 13: Model of the migration of natural gas and the process of overpressure vertical transfer in the LD-B Wellblock.

sandstones for more than $1 \mathrm{Ma}$ and that such sealing ability is common in basins $[51,54]$.

\subsubsection{Model for the Overpressure Generation in the Ledong} Slope. This study recognizes that the overpressure caused by disequilibrium compaction can reach about 1.5-1.6 in $\mathrm{N}_{1} \mathrm{~h}$ and $\mathrm{N}_{1} \mathrm{~m}$ in the Ledong Slope, and the overpressure vertical transfer accounts for most of the observed high-magnitude overpressure. Based on this knowledge, a model of overpressure generation in the LD-B Wellblock can be established and used as the basis for overpressure identification and pressure prediction in the future.

The $\mathrm{N}_{1}$ s source rocks have the potential to develop highmagnitude overpressure with a mudstone content greater than $75 \%$, deposition rate exceeding $280 \mathrm{~m} / \mathrm{Ma}$, organic matter content greater than $1.55 \%$, maturity higher than $1.3 \sim 2.0 \%$, and the pressure coefficient reaching 1.9-2.0. When the opening faults/microfractures connect source rocks and reservoirs, overpressure is transferred accompanied by the migration of natural gas along the faults/fractures, resulting in high overpressure in the channel sandbodies of the shallow $\mathrm{N}_{1} \mathrm{~h}$ and $\mathrm{N}_{1} \mathrm{~m}$ formations (Figure 13). Faults/microfractures are rarely developed in the Miocene and Quaternary formations, so the overpressure is confined to the fault-affected $\mathrm{N}_{1} \mathrm{~h}$ (Figure 13). The gasbearing channel sandbodies are isolated in LD-B gas reservoirs, indicating well lateral sealing conditions. The thick and widely distributed mudstone above the gas reservoir is not affected by faults/fractures and exhibits good vertical sealing. Therefore, overpressure transferred by faults/fractures can be preserved for a long time in ultralow permeability and well-sealed reservoirs.

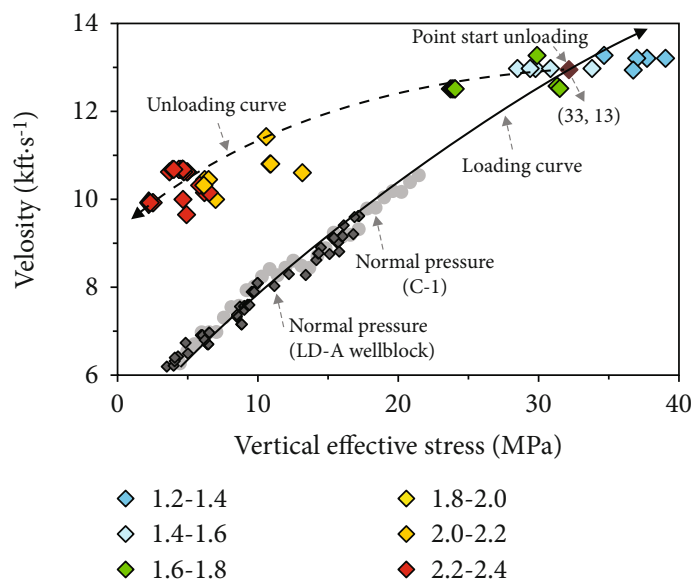

FIGURE 14: Crossplot of vertical effective stress versus sonic velocity in LD-B Wellblock, showing the first unloading point.

Overpressure sequences are usually considered undesirable targets for oil and gas exploration because of the increased risk of caprock or fault seal failure [58]. Hydraulic fracturing occurs when the overpressure exceeds the fracture pressure of the cap rock, which leads to fluid and overpressure dissipation. Notably, the fracture pressure gradient increases significantly with increasing overpressure (Figure 5), a phenomenon known as pore pressure-stress coupling [59]. The pore pressure-stress coupling in turn increases the ability of the caprock to maintain the maximum overpressure $[38,59]$.

6.3. Pore Pressure Prediction from Log Data. Understanding the causes of overpressure is the basis for accurate pore 


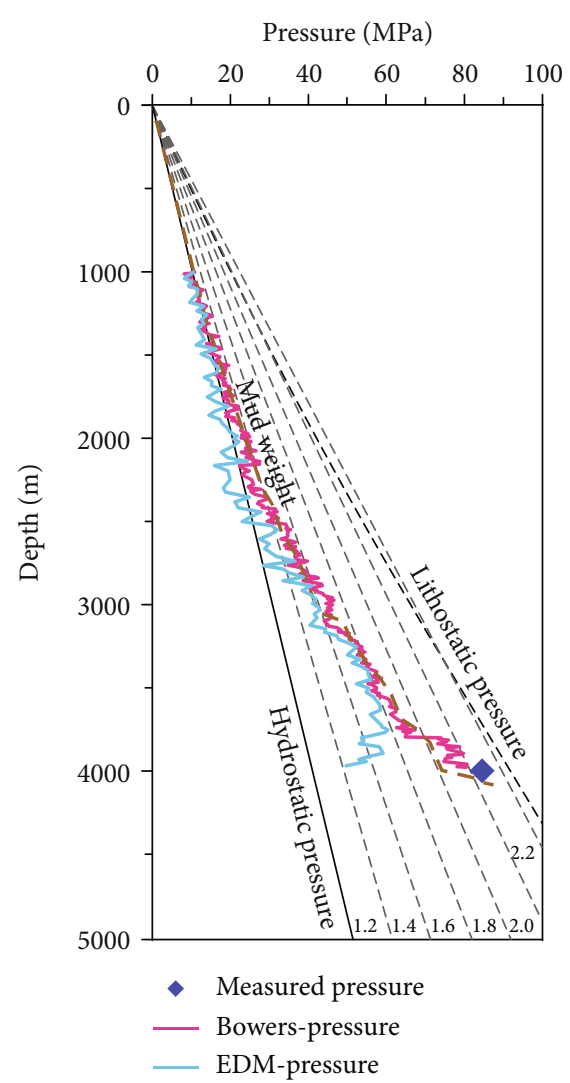

(a)

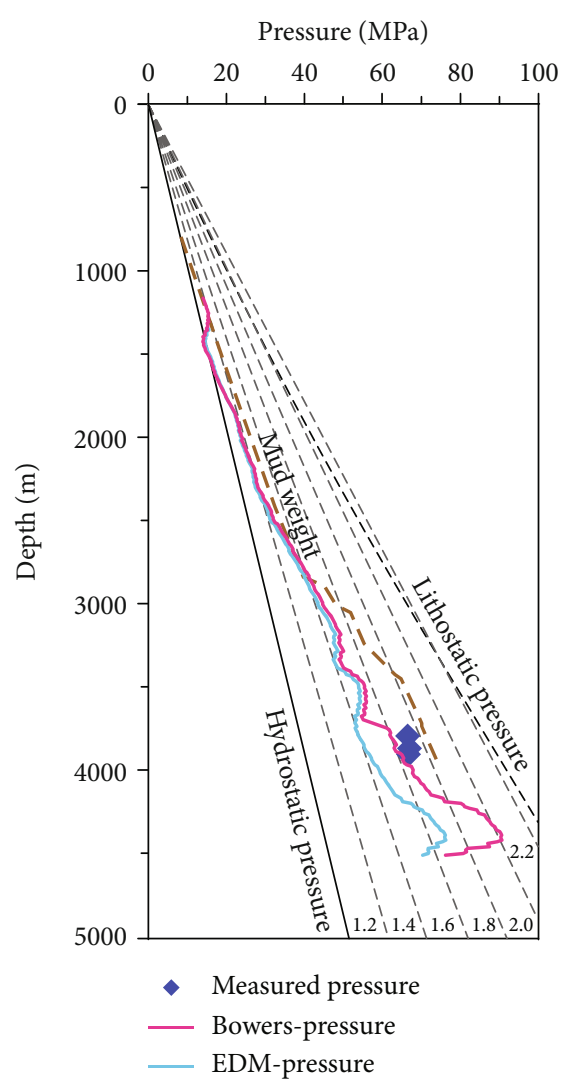

(b)

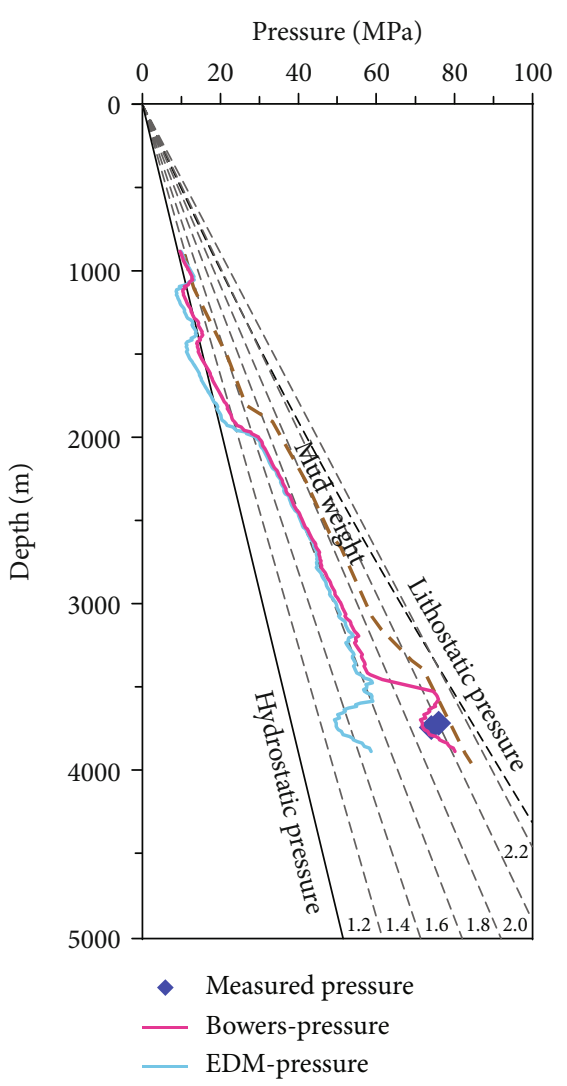

(c)

FIGURE 15: Pore pressure prediction of three wells in the Ledong Slope in Yinggehai Basin. Bowers-Pressure means the pore pressure is predicted by the Bowers method; EDM-Pressure means the pore pressure is predicted by equivalent depth method.

pressure prediction; different overpressure-generating mechanisms affect the responses of rock properties to overpressure. The commonly used pressure prediction methods include the equivalent depth, Eaton, and Bowers methods, all of which are carried out based on the sonic transit time. The equivalent depth method predicts overpressure depending on the abnormally high value of porosity, and it is assumed that the overpressure is mainly generated by disequilibrium compaction of mudstone. As an empirical relationship, the Eaton method does not truly indicate the cause of overpressure, although the pressure prediction results can be modified by adjusting the Eaton index. When the loading and unloading curves are established, the Bowers method systematically considers the mechanism of disequilibrium compaction and unloading overpressure $[11,12]$.

Due to the overpressure in the LD-B Wellblock is a combination of the results of multiple mechanisms, including disequilibrium compaction and overpressure vertical transfer, the Bowers method is used to predict the pore pressure. The sonic transit time is converted into sonic velocity, and the vertical effective stress-sonic velocity relationship is constructed for the LD-B Wellblock (Figure 14). The key parameters for the loading-unloading equations can be determined as follows: $A=403.51, B=0.8598, V_{\max }=13 \mathrm{kft} / \mathrm{s}, \sigma_{\max }=33 \mathrm{MPa}$, and $U=4.37$.
The calculation equations of pore pressure in the loading and unloading cases are

$$
P_{l o}=\sigma_{\mathrm{v}}-\left(\frac{V-5000}{403.51}\right)^{1 / 0.8598},
$$

and

$$
P_{u l o}=\sigma_{\mathrm{v}}-\left(\frac{V-5000}{403.51}\right)^{4.37 / 0.8598}(33)^{1-4.37} \text {, }
$$

where $P_{l o}$ and $P_{u l o}$ are the pore pressure in loading and unloading case, respectively, MPa.

The pore pressure prediction results show that the shallower intervals in well B-1 are mainly normal pressure, the pressure equation under loading conditions is adopted in the prediction, and the predicted results also show normal values. The measured pressure at about $4000 \mathrm{~m}$ shows obvious unloading characteristics, and the predicted pressure under unloading conditions is basically consistent with the measured pressure (Figure 15(a)). Moreover, the pore pressure calculated using the equivalent depth method is also superimposed on the plot; for the loading process at shallow depths, the two results are similar. The pressures predicted by the equivalent 
depth method can approximately reflect the mudstone pressure, but seriously underestimates the reservoir pressure in the target sections (Figure 15(a)). This implies that the transfer overpressure often does not have the corresponding logging anomaly amplitude. The Bowers method can be applied to pore pressure prediction in wells D-1 and E-7, which are nearby the LD-B Wellblock, and more reliable pressure prediction results can also be obtained (Figures 15(b) and 15(c)).

It is worth noting that the pressure predicted by the equivalent depth method reflects continuous pressure changes in mudstone. However, the predicted pressure of sandstone only reflects the pressure in the sandbodies, which are affected by overpressure vertical transfer, rather than the pressure distribution trend of the whole strata. The pressure in any interval should be between the predicted pressure of mudstone and the pressure of sandstone. To determine the pressure in sandstone, the relationship between sandbodies and faults/fractures should be confirmed. If the sandstone does not have the conditions necessary to connect with the deep overpressure systems, the pressure may be basically close to the mudstone pressure. When the sandstone is connected by faults with the higher overpressure sandstone, the pressure should refer to as the prediction pressure by the Bowers method.

\section{Conclusions}

(1) The disequilibrium compaction of mudstone and fluid expansion mechanisms are insufficient to explain the high-magnitude overpressure in reservoirs in the LD-B Wellblock in the Yinggehai Basin. All the high-magnitude overpressure points deviate from the loading curve and show a typical response of the unloading mechanism. Allo-source overpressure caused by vertical transfer in the nondiapir zone is still an extremely important overpressure mechanism

(2) The ultradeep buried Miocene source rocks developed high-amplitude overpressure, which ensured a sufficient source for overpressure transfer fluid. The hidden faults/microfractures connecting source rocks and reservoirs provided a possible pathway for overpressure vertical transfer. The formation time of allosource overpressure was no earlier than $1.5 \mathrm{Ma}$, allowed for overpressure preservation in well-sealed lenticular sandbodies

(3) The allo-source overpressure related to vertical transfer does not always have enough logging response amplitudes corresponding to the overpressure values. The pore pressure calculated by the Bowers method is in good agreement with the measured pressure, especially the vertically transferred overpressure can be accurately predicted by the Bowers method

(4) Recognitions of overpressure mechanisms and pressure prediction provide new insight into highmagnitude overpressure generation and natural gas formation, which is especially meaningful for predrilling pressure prediction in nondiapir zones of the Yinggehai Basin, and it helps to reduce drilling risks

\section{Data Availability}

The main data used to support the findings of this study are included within the article, and the others are available from the corresponding author upon request.

\section{Conflicts of Interest}

The authors declare that they have no competing interests.

\section{Acknowledgments}

This study has been funded by the Strategic Priority Research Program of the Chinese Academy of Sciences (XDA14010202), National Science and Technology Major Project (2017ZX05008-004), and National Natural Science Foundation of China (U20B2014). We are thankful to the Zhanjiang Branch of the CNOOC for providing the original data. Editors and reviewers are appreciated for their critical comments and suggestions, which significantly improve the quality of this work.

\section{References}

[1] M. J. Osborne and R. E. Swarbrick, "Mechanisms for generating overpressure in sedimentary basins: a reevaluation," $A A P G$ Bulletin, vol. 81, no. 6, pp. 1023-1041, 1997.

[2] M. R. P. Tingay, R. R. Hillis, R. E. Swarbrick, C. K. Morley, and A. R. Damit, "Origin of overpressure and pore-pressure prediction in the Baram province, Brunei," AAPG Bulletin, vol. 93, no. 1, pp. 51-74, 2009.

[3] M. R. P. Tingay, C. K. Morley, A. Laird et al., "Evidence for overpressure generation by kerogen-to-gas maturation in the northern Malay Basin," AAPG Bulletin, vol. 97, no. 4, pp. 639-672, 2013.

[4] A. R. Najibi, M. Ghafoori, G. R. Lashkaripour, and M. R. Asef, "Reservoir geomechanical modeling: in-situ stress, pore pressure, and mud design," Journal of Petroleum Science and Engineering, vol. 151, pp. 31-39, 2017.

[5] H. Raimbourg, R. Thiéry, M. Vacelet et al., "Organic matter cracking: a source of fluid overpressure in subducting sediments," Tectonophysics, vol. 721, pp. 254-274, 2017.

[6] K. Nifuku, Y. Kobayashi, Y. Araki, T. Ashida, and T. Taniwaki, "Overpressure evolution controlled by spatial and temporal changes in the sedimentation rate: insights from a basin modelling study in offshore Suriname," Basin Research, vol. 33, pp. 1293-1314, 2020.

[7] M. R. Tingay, R. R. Hillis, R. E. Swarbrick, C. K. Morley, and A. R. Damit, "Vertically transferred' overpressures in Brunei: evidence for a new mechanism for the formation of highmagnitude overpressure," Geology, vol. 35, no. 11, pp. 10231026, 2007.

[8] R. J. Javanshir, G. W. Riley, S. J. Duppenbecker, and N. Abdullayev, "Validation of lateral fluid flow in an overpressured sand-shale sequence during development of AzeriChirag-Gunashli oil field and Shah Deniz gas field: South Caspian Basin, Azerbaijan," Marine and Petroleum Geology, vol. 59, pp. 593-610, 2015.

[9] X. R. Luo and G. Vasseur, "Overpressure dissipation mechanisms in sedimentary sections consisting of alternating mud- 
sand layers," Marine and Petroleum Geology, vol. 78, pp. 883$894,2016$.

[10] X. R. Luo, J. H. Yang, and Z. F. Wang, "The overpressuring mechanisms in aquifers and pressure prediction in basins," Geological Review, vol. 46, no. 1, pp. 22-31, 2000.

[11] J. C. Zhang, "Pore pressure prediction from well logs: methods, modifications, and new approaches," Earth-Science Reviews, vol. 108, no. 1-2, pp. 50-63, 2011.

[12] K. Suwannasri, W. Promrak, S. Utitsan et al., "Reducing the variation of Eaton's exponent for overpressure prediction in a basin affected by multiple overpressure mechanisms," Interpretation, vol. 2, no. 1, pp. SB57-SB68, 2014.

[13] G. S. Yardley and R. E. Swarbrick, "Lateral transfer: a source of additional overpressure?," Marine and Petroleum Geology, vol. 17, no. 4, pp. 523-537, 2000.

[14] B. Y. Gao and P. B. Flemings, "Pore pressure within dipping reservoirs in overpressured basins," Marine and Petroleum Geology, vol. 80, pp. 94-111, 2017.

[15] X. R. Luo, W. L. Dong, J. H. Yang, and W. Yang, "Overpressuring mechanisms in the Yinggehai Basin, South China Sea," AAPG Bulletin, vol. 87, no. 4, pp. 629-642, 2003.

[16] S. Dasgupta, R. Chatterjee, and S. P. Mohanty, "Magnitude, mechanisms, and prediction of abnormal pore pressure using well data in the Krishna-Godavari Basin, east coast of India," AAPG Bulletin, vol. 100, no. 12, pp. 1833-1855, 2016.

[17] C. Y. Fan, Z. L. Wang, A. G. Wang et al., "Identification and calculation of transfer overpressure in the northern Qaidam Basin, Northwest China," AAPG Bulletin, vol. 100, no. 1, pp. 23-39, 2016.

[18] G. L. Bowers, "Pore pressure estimation from velocity data: accounting for overpressure mechanisms besides undercompaction," SPE Drilling \& Completion, vol. 10, no. 2, pp. 8995, 1995.

[19] G. L. Bowers, "Detecting high overpressure," Leading Edge, vol. 21, no. 2, pp. 174-177, 2002.

[20] G. Karthikeyan, J. Dutta, A. Kumar, N. Bhardwaj, and N. Sinha, "Fault-related overpressure in the Krishna-Godavari Basin, India," Interpretation, vol. 8, no. 1, pp. T183-T193, 2019.

[21] N. Schofield, S. Holford, A. Edwards, N. Mark, and S. Pugliese, "Overpressure transmission through interconnected igneous intrusions," AAPG Bulletin, vol. 104, no. 2, pp. 285-303, 2020.

[22] E. Hoskin, S. O'Connor, S. Robertson et al., "Influence of faulting on reservoir overpressure distribution in the northern Carnarvon Basin," The APPEA Journal, vol. 55, no. 1, pp. 1-14, 2015.

[23] D. M. Audet, "Compaction and overpressuring in Pleistocene sediments on the Louisiana Shelf, Gulf of Mexico," Marine and Petroleum Geology, vol. 13, no. 5, pp. 467-474, 1996.

[24] R. E. Swarbrick, M. J. Osborne, D. Grunberger et al., "Integrated study of the Judy Field (Block 30/7a) - an overpressured Central North Sea oil/gas field," Marine and Petroleum Geology, vol. 17, no. 9, pp. 993-1010, 2000.

[25] R. W. Lahann, "Gulf of Mexico overpressure and clay diagenesis without unloading: an anomaly?," AAPG Bulletin, vol. 101, no. 11, pp. 1859-1877, 2017.

[26] C. Hermanrud and O. Undertun, "Resolution limits of fluid overpressures from mineralogy, porosity, and sonic velocity variations in North Sea mudrocks," AAPG Bulletin, vol. 103, no. 11, pp. 2665-2695, 2019.

[27] A. Q. Liu, C. W. Fan, Y. P. Wu, and F. Li, "Study on prediction method of allochthonous pressure based on transfer mode in high temperature and high pressure field of South China Sea," China Offshore Oil and Gas, vol. 33, no. 1, pp. 50-55, 2021.

[28] X. N. Xie, S. T. Li, W. L. Dong, and Q. M. Zhang, “Overpressure development and hydrofracture in the Yinggehai Basin, South China Sea," Journal of Petroleum Geology, vol. 22, no. 4, pp. 437-454, 1999.

[29] F. Hao, W. H. Dong, H. Y. Zou, and X. S. Yang, "Overpressure fluid flow and rapid accumulation of natural gas in Yinggehai Basin," Acta Petrolei Sinica, vol. 24, no. 6, pp. 7-12, 2003.

[30] C. Lei, J. Y. Ren, P. D. Clift, Z. F. Wang, X. S. Li, and C. X. Tong, "The structure and formation of diapirs in the Yinggehai-Song Hong Basin, South China Sea," Marine and Petroleum Geology, vol. 28, no. 5, pp. 980-991, 2011.

[31] W. Zhou, Y. H. Xie, X. S. Li, Q. Cao, R. C. Song, and C. X. Tong, "Exploration of relationship between formation and evolution of pressure compartment and accumulation in Yinggehai Baisn, China," Journal of Chengdu University of technology (Science and Technology Edition), vol. 41, no. 6, pp. 760767, 2014.

[32] X. L. Yin, S. T. Li, J. H. Yang, and Q. M. Zhang, "Correlations between overpressure fluid activity and fault system in Yinggehai Basin," Acta Geoscientia Sinica, vol. 23, no. 2, pp. 141-146, 2002.

[33] A. Q. Liu, J. X. Zhou, C. W. Fan, F. Fan, and Y. P. Wu, "Predrilling pressure prediction problems and solutions in the HTHP strata of Yinggehai-Qiongdongnan Basin," Natural Gas Industry, vol. 35, no. 2, pp. 21-26, 2015.

[34] Y. H. Xie, "Models of pressure prediction and new understandings of hydrocarbon accumulation in the Yinggehai Basin with high temperature and super-high pressure," Natural Gas Industry, vol. 31, no. 12, pp. 21-25, 2011.

[35] X. S. Li, J. H. Yang, C. W. Fan et al., "New progress and key technologies for high temperature and overpressure natural gas exploration in the northern part of South China Sea: taking the Ledong slope belt of Yinggehai Basin as an example," China Offshore Oil and Gas, vol. 32, no. 1, pp. 23-31, 2020.

[36] H. Liang, S. S. Guo, and G. L. Liao, "Application of pressure monitoring technolog while drilling in non-undercompaction overpressure formations in Ledong area of Yingqiong Basin," China Offshore Oil and Gas, vol. 32, no. 4, pp. 147-151, 2020.

[37] B. J. Huang, X. M. Xiao, and X. X. Li, "Geochemistry and origins of natural gases in the Yinggehai and Qiongdongnan basins, offshore South China Sea," Organic Geochemistry, vol. 34, no. 7, pp. 1009-1025, 2003.

[38] R. Liu, J. Liu, W. Zhu et al., "In situ stress analysis in the Yinggehai Basin, northwestern South China Sea: implication for the pore pressure-stress coupling process," Marine and Petroleum Geology, vol. 77, pp. 341-352, 2016.

[39] C. Li, X. R. Luo, L. K. Zhang et al., "Overpressure generation mechanisms and its distribution in the Paleocene Shahejie Formation in the Linnan Sag, Huimin Depression, Eastern China," Energies, vol. 12, no. 16, pp. 3183-3206, 2019.

[40] J. X. Dai, "Coal-derived gas theory and its discrimination," China Science Bulletin, vol. 63, no. 14, pp. 1291-1305, 2018.

[41] L. L. Shui, R. Liang, X. H. Meng, L. Y. Guo, and K. W. Xu, "Characteristics of fluid inclusions in quartz fractures in Ledong area of Yinggehai Basin and its constraints on gas accumulation," Sedimentary Geology and Tethyan Geology, vol. 40, no. 1, pp. 45-52, 2020. 
[42] J. H. Yang, B. J. Huang, and D. Y. Chen, "Accumulation condition and exploration potential of low porosity and ultralow permeability sandstone gas reservoirs on the depression slope belt of Yinggehai Basin," China Offshore Oil and Gas, vol. 30, no. 1, pp. 11-21, 2018.

[43] B. F. Zhao, H. H. Chen, L. T. Kong, Q. R. Wang, and R. Liu, "Vertical migration system and its control on natural gas accumulation in Yinggehai Basin," Earth Science - Journal of China University of Geosciences, vol. 39, no. 9, pp. 1323-1332, 2014.

[44] W. Duan, C. F. Luo, X. S. Huang, B. Lv, X. D. Zuo, and L. Ding, "Effects of formation overpressure on mudstone diagenesis and its geological significance in LD block of Yinggehai Basin," Geological Science and Technology Information, vol. 34, no. 4, pp. 43-50, 2015.

[45] C. Li, X. R. Luo, and L. K. Zhang, "Overpressure responses for chemical compaction of mudstones and the pore pressure prediction," Journal of China University of Mining \& Technology, vol. 49, no. 5, pp. 951-973, 2020.

[46] K. Katahara, "Overpressure and shale properties: stress unloading or smectite-illite transformation," in 76th Annual International Meeting SEG, vol. 12, pp. 1520-1524, New Orleans, LA, USA, January 2006.

[47] R. Nygård, M. Gutierrez, R. K. Bratli, and K. Høeg, "Brittleductile transition, shear failure and leakage in shales and mudrocks," Marine and Petroleum Geology, vol. 23, no. 2, pp. 201-212, 2006.

[48] R. Jia, The Integrity of Caprocks and Gas Accumulation in Yingqiong Basin, Dissertation, Northeast Petroleum University, 2018.

[49] W. T. Li, Z. Li, B. Liu, H. L. Peng, and W. B. Deng, "The status quo and prospects for pore pressure prediction technology in Yingqiong Basin of South China Sea," Offshore Oil, vol. 40, no. 3, pp. 8-12, 2020.

[50] X. R. Luo and G. Vasseur, "Contributions of compaction and aquathermal pressuring to geopressure and the influence of environmental conditions," AAPG Bulletin, vol. 76, no. 10, pp. 1550-1559, 1992.

[51] X. R. Luo and G. Vasseur, "Sealing efficiency of shales," Terra Nova, vol. 9, no. 2, pp. 71-74, 1997.

[52] R. W. Lahann and R. E. Swarbrick, "Overpressure generation by load transfer following shale framework weakening due to smectite diagenesis," Geofluids, vol. 11, no. 4, p. 375, 2011.

[53] H. Yu and F. J. Hilterman, "The effect of pressure on rock properties in the Gulf of Mexico: comparison between compaction disequilibrium and unloading," Interpretation, vol. 2, no. 1, pp. SB1-SB15, 2014.

[54] D. J. Grauls and J. M. Baleix, "Role of overpressures and _in situ_stresses in fault-controlled hydrocarbon migration: a case study," Marine and Petroleum Geology, vol. 11, no. 6, pp. 734742, 1994.

[55] J. Yang and B. Huang, "Origin and migration model of natural gas in L gas field, eastern slope of Yinggehai Sag, China," Petroleum Exploration and Development, vol. 46, no. 3, pp. 471-481, 2019.

[56] C. W. Fan, "The identification and characteristics of migration system induced by high pressure, and its hydrocarbon accumulation process in the Yingqiong Basin," Oil and Gas Geology, vol. 39, no. 2, pp. 254-267, 2018.

[57] X. R. Luo and G. Vasseur, "Natural hydraulic cracking: numerical model and sensitivity study," Earth and Planetary Science Letters, vol. 201, no. 2, pp. 431-446, 2002.
[58] M. Foschi and J. A. Cartwright, "Seal failure assessment of a major gas field via integration of seal properties and leakage phenomena," AAPG Bulletin, vol. 104, no. 8, pp. 1627-1648, 2020.

[59] R. R. Hills, "Coupled changes in pore pressure and stress in oil fields and sedimentary basins," Petroleum Geoscience, vol. 7, no. 4, pp. 419-425, 2001. 